\title{
Augmentations to the Noah Model Physics for Application to the Yellow River Source Area. Part I: Soil Water Flow
}

\author{
DONGHAI ZHENG \\ Faculty of Geo-Information Science and Earth Observation, and Faculty of Engineering Technology, \\ University of Twente, Enschede, Netherlands \\ ROGIER VAN DER VELDE AND ZHONGBO SU \\ Faculty of Geo-Information Science and Earth Observation, University of Twente, Enschede, Netherlands \\ XIN WANG AND JUN WEN \\ Key Laboratory of Land Surface Process and Climate Change in Cold and Arid Regions, Cold and Arid Regions \\ Environmental and Engineering Research Institute, Chinese Academy of Sciences, Lanzhou, China \\ MARTIJN J. BOOIJ AND ARJEN Y. HOEKSTRA \\ Faculty of Engineering Technology, University of Twente, Enschede, Netherlands \\ YINGYING CHEN \\ Institute of Tibetan Plateau Research, Chinese Academy of Sciences, Beijing, China
}

(Manuscript received 12 October 2014, in final form 31 March 2015)

\begin{abstract}
This is the first part of a study focusing on evaluating the performance of the Noah land surface model (LSM) in simulating surface water and energy budgets for the high-elevation source region of the Yellow River (SRYR). A comprehensive dataset is utilized that includes in situ micrometeorological and profile soil moisture and temperature measurements as well as laboratory soil property measurements of samples collected across the SRYR. Here, the simulation of soil water flow is investigated, while Part II concentrates on the surface heat flux and soil temperature simulations. Three augmentations are proposed: 1) to include the effect of organic matter on soil hydraulic parameterization via the additivity hypothesis, 2) to implement the saturated hydraulic conductivity $K_{s}$ as an exponentially decaying function with soil depth, and 3) to modify the vertical root distribution to represent the Tibetan conditions characterized by an abundance of roots in the topsoil. The diffusivity form of Richards' equation is further revised to allow for the simulation of soil water flow across soil layers with different hydraulic properties. Usage of organic matter for calculating the porosity and soil suction improves the agreement between the estimates and laboratory measurements, and the exponential function together with the Kozeny-Carman equation best describes the in situ $K_{s}$. Through implementation of the modified hydraulic parameterization alone, the soil moisture underestimation in the upper soil layer under wet conditions is resolved, while the soil moisture profile dynamics are better captured by also including the modified root distribution.
\end{abstract}

\section{Introduction}

Global warming is expected to continue in the future according to outcomes of atmospheric general circulation models (AGCMs; IPCC 2013). Within AGCMs, land

Corresponding author address: Donghai Zheng, University of Twente, P.O. Box 217, 7500 AE Enschede, Netherlands.

E-mail: d.zheng@utwente.nl surface models (LSMs) provide the lower boundary conditions in the form of moisture and energy exchanges at the land-atmosphere interface. To make credible predictions of climate change, LSMs evolved from a simple bucket model (Manabe 1969) to more sophisticated soilvegetation-atmosphere transfer (SVAT) schemes (Dai et al. 2003; Ek et al. 2003; Lawrence et al. 2011; Niu et al. 2011; Sellers et al. 1986) to better represent the complex interplay of processes linked to vegetation, soil, and 
snow. However, state-of-the-art LSMs still have difficulties with reliably simulating the states that drive heat (Decker et al. 2012; Jiménez et al. 2011) as well as water (Dirmeyer et al. 2004, 2006b) fluxes. Further improvement of LSMs and validation against observations remain, therefore, imperative.

Soil moisture is a key state variable controlling the partitioning of available energy at the land surface between sensible and latent heat, as well as determining the partitioning of rainfall between subsoil drainage, surface runoff $R_{\text {surf }}$, and evaporation. Thus, it is crucial to reliably simulate soil water flow processes to provide realistic initial states to the models that are used to simulate climate change and its impact on the terrestrial water cycle. However, large differences and biases exist among the soil moisture products generated by various LSMs driven with the same meteorological forcing (Dirmeyer et al. 2006a; Xia et al. 2014) because of different model physics, structure, and parameter choices. For instance, several vertical root distribution schemes (i.e., root depth and density) are implemented by the current LSMs (Zeng 2001), and the diversity of soil hydraulic functions as well as hydraulic parameters also pose a high uncertainty (Decharme et al. 2011; Shao and Irannejad 1999). Moreover, the LSMs have originally been developed for largescale applications and numerical efficiency. Therefore, the presence of irrigation and groundwater processes is often ignored (e.g., Xia et al. 2014), and the number of soil layers is limited and extends down to a few meters (e.g., Gulden et al. 2007). Besides, the soil profile is assumed homogeneous, and either the diffusivity form of Richards' equation (e.g., Balsamo et al. 2009; Liang et al. 1996) or a force-restore approach (Decharme et al. 2006) is employed for the soil water flow simulation by LSMs that does not accommodate for transport across layers with different hydraulic properties.

Recently, Chen et al. (2013), Su et al. (2013), and Xue et al. (2013) have reported on the inability of LSMs to reproduce the soil moisture and temperature profiles measured by newly developed in situ monitoring networks across the central and eastern parts of the Tibetan Plateau (Su et al. 2011; Yang et al. 2013). A major reason for the weak performance of LSMs in this region is the absence of vertical soil heterogeneity within model structures (Chen et al. 2013; Yang et al. 2005). Particularly, many roots are present in the upper soil layer of Tibetan ecosystems as an adaptation to the harsh Tibetan environment (Yang et al. 2009a). This leads to the accumulation of organic matter in the topsoil (Yang et al. 2009b, hereafter Y09b) and causes a soil stratification (Chen et al. 2012). Organic matter and living and decayed root systems share a large volume of the topsoil, affecting the soil structure as well as its hydraulic and thermal properties (Chen et al. 2012). Organic matter generally has a higher porosity, hydraulic conductivity, and thermal heat capacity, while a lower thermal heat conductivity and less suction needs to be applied to release water as compared to mineral soils (de Vries 1963; Lawrence and Slater 2008; Letts et al. 2000).

Previous studies have shown that the vertical soil heterogeneity as well as the effect of organic matter and root systems not only affects the thermal and moisture regimes at the ground (Beringer et al. 2001; Letts et al. 2000; Yang et al. 2005), but also the dynamic interactions with the overlaying atmosphere (Lawrence and Slater 2008; Rinke et al. 2008). It is, therefore, indispensable for the applicability of AGCMs to polar and boreal ecosystems that the organic matter as well as the vertical soil heterogeneity is considered by LSMs. However, parameterizations for organic soil types are typically not implemented by the stateof-the-art LSMs. In the past, Beringer et al. (2001) and Letts et al. (2000) have studied the soil water flow through a column of pure organic material overlaying mineral soil layers, while Lawrence and Slater (2008) conceptualized the soil water transport through a mixture of coexisting organic and mineral components whose physical properties are additive. These two approaches have been developed specifically for the Arctic and boreal organic soils and its applicability to the Third Pole Environment, as the Tibetan Plateau is also referred to, is yet to be proven. Although Chen et al. (2012) have recently investigated the effect of organic soil on soil thermal parameterization for grasslands in central Tibet, additional work is needed to assess the impact of organic soil on soil hydraulic parameterization as well as the simulated surface energy and water budgets.

In this investigation, we seek to further improve a stateof-the-art Noah LSM (Ek et al. 2003) in its ability to simultaneously produce soil moisture and temperature profiles measured in the source region of the Yellow River (SRYR) on the northeastern Tibetan Plateau. In this twopart series, we study the model physics associated with the soil water flow simulation through comparisons of the soil parameterization with hydraulic properties measured in the laboratory and through comparisons of simulations with in situ soil moisture profile measurements. Three augmentations are made. First, the effect of organic matter on soil hydraulic properties is considered via the "additivity" hypothesis (Zeiliguer et al. 2000). Second, the saturated hydraulic conductivity $K_{s}$ is implemented as an exponentially decaying function of soil depth according to Beven (1982). Third, the vertical root distribution scheme is modified to represent the abundance of roots in the topsoil that is characteristic for the Tibetan conditions. The impact of the augmentations on the simulated surface energy and water budgets is evaluated via intercomparisons, whereas specifically the sensible $H$ and latent heat flux (LE) 


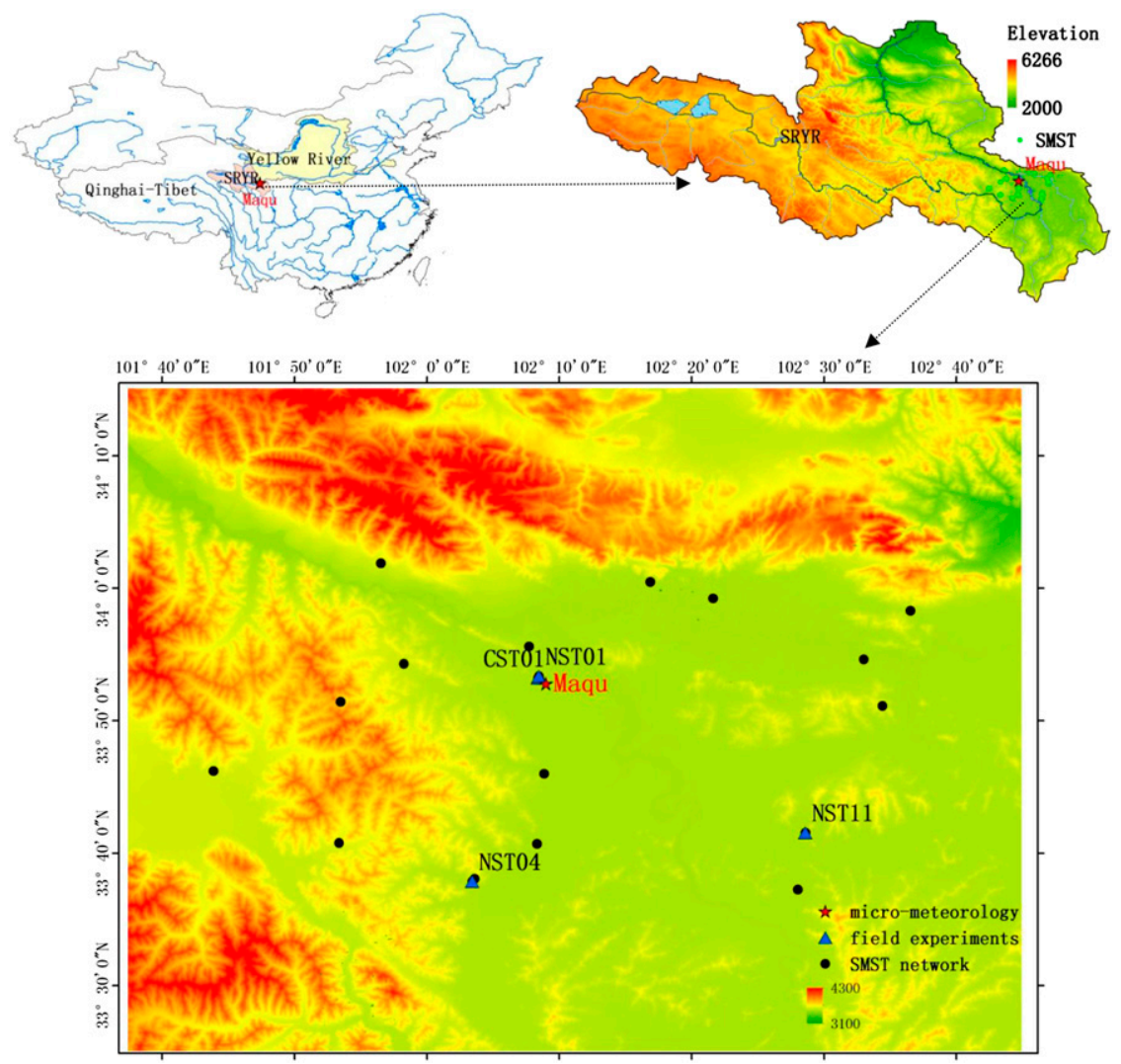

FIG. 1. (top) Location of Maqu station in the SRYR in China and (bottom) the field observation system and experimental sites.

computations are assessed using in situ measurements. In Zheng et al. (2015, hereafter Part II), we focus on the simulation of surface heat flux and soil heat flow.

The structure of this paper is as follows. Section 2 describes the in situ micrometeorological measurements and the soil moisture and temperature profile measurements as well as the soil properties measured in the laboratory. Section 3 introduces the soil water flow and root water uptake components of Noah. Section 4 provides a description of the augmentations made to the Noah model physics. Section 5 presents comparisons of the modified hydraulic parameterization and measured soil properties. Section 6 provides a performance assessment of the soil moisture profiles simulated by Noah with different options. The impact of the improved soil moisture simulations on the calculated surface energy and water budgets is evaluated in section 7 , and section 8 summarizes the findings of this study.

\section{Observations and experiments}

\section{a. Maqu observation station}

Maqu Climate and Environment Observation Station (Fig. 1) is located in the SRYR in a landscape dominated by alpine meadows (e.g., Cyperaceae and Gramineae) at elevations varying from 3200 to $4200 \mathrm{~m}$. Cold dry winters and rainy summers are characteristic for its climate, with a mean annual air temperature of $1.2^{\circ} \mathrm{C},-10^{\circ} \mathrm{C}$ for the coldest month (January) and $11.7^{\circ} \mathrm{C}$ for the warmest month (July). The groundwater level is about $8.5-10.0 \mathrm{~m}$ below the soil surface.

Maqu is a micrometeorological station equipped with a 20-m planetary boundary layer (PBL) tower providing wind speed and direction, air humidity, and temperature at five levels; instrumentation for measuring four radiation components; and an eddy covariance (EC) system installed at a height of $3.2 \mathrm{~m}$. Table 1 lists the equipment deployed and the measured hydrometeorological variables. Across an area of $40 \mathrm{~km} \times 80 \mathrm{~km}$ centered on Maqu station, a network of 20 soil moisture and soil temperature (SMST) monitoring sites has been operational since 2008 (Dente et al. 2012). This regionalscale SMST network is part of the Tibetan Plateau Observatory (Tibet-Obs; Su et al. 2011) and has been designed to contribute to the calibration-validation of satellite-based soil moisture products as well as to an improved understanding of land processes on the plateau. Two SMST sites (CST01 and NST01) of the 
TABLE 1. Equipment deployed and the hydrometeorological variables measured at Maqu station.

\begin{tabular}{|c|c|c|c|}
\hline System & Items & Level (m) & Sensor \\
\hline \multirow[t]{6}{*}{ PBL tower } & Wind speed and direction & $2.35,4.2,7.17,10.13,18.15$ & Gill WindSonic 2D \\
\hline & Air temperature & & Vaisala HMP45C \\
\hline & Humidity & & \\
\hline & Air pressure & 2.0 & Vaisala CS105 \\
\hline & Radiation flux & 1.5 & Kipp and Zonen CNR1 \\
\hline & Precipitation & & $\begin{array}{l}\text { Young } 52202 \text { tipping-bucket } \\
\text { rain gauge }\end{array}$ \\
\hline \multirow[t]{3}{*}{ Eddy covariance system } & Wind fluctuation & 3.2 & $\begin{array}{l}\text { CSAT3 3D sonic } \\
\text { anemometer }\end{array}$ \\
\hline & Sensible heat flux & & Campbell LI-COR 7500 \\
\hline & Latent heat flux & & \\
\hline SMST & $\begin{array}{l}\text { Soil temperature and soil } \\
\text { moisture }\end{array}$ & $-0.05,-0.1,-0.2,-0.4,-0.8$ & EC-TM ECH ${ }_{2} \mathrm{O}$ probe \\
\hline
\end{tabular}

Tibet-Obs are situated in the vicinity of Maqu station and are used for the presented analyses.

The time period under investigation covers the majority of the monsoon season starting on 8 June and ending on 30 September 2010. This episode is selected to avoid the impact of the cold season (e.g., snowpack and frozen soil) on the assessment of Noah's soil water flow and heat transport model physics. All the data were processed to a value for every 30-min interval within this episode, whereby the ground surface temperature is computed from measured upward and downward longwave radiations as in Zheng et al. (2014). Additional details for the measurements and data processing can be found in Dente et al. (2012) and Zheng et al. (2014).

\section{b. Field and laboratory experiments}

Soil samples were collected at two SMST sites (CST01 and NST01) near the micrometeorological station, as well as two sites (NST04 and NST11) located in a wetland environment (shown in Fig. 1) to quantify the soil texture and hydraulic properties through laboratory analyses in July 2013. Two or three soil profiles were obtained from each site, with samples taken at depths of $0.1,0.3$, and $0.6 \mathrm{~m}$. Duplicates of undisturbed soil samples were collected by soil-cutting ring augers, whereby the hydraulic characterization was complemented by field measurement of the saturated hydraulic conductivity with the Guelph Permeameter manufactured by Soilmoisture Equipment Corp.

The soil samples were transported to the laboratory for precise measurement of the soil texture (sand, clay, and silt), organic carbon mass content $m_{\text {soc }}$, bulk density $\rho_{b}$, porosity $\theta_{s}$, soil water retention curve, and soil heat conductivity $\lambda$. Soil texture was measured with a Malvern Mastersizer 2000 particle size analyzer, and organic carbon mass content was measured with a Total Organic Carbon Analyzer (Shimadzu TOC-VCPH). Soil porosity is calculated from the difference of the saturated and dry soil weight of the cutting ring with a known volume $\left(100 \mathrm{~cm}^{3}\right)$ and weight, and bulk density is calculated from the dry soil weight. Soil water contents associated with 11 pressure heads from 0 to 15 bars were performed with the Pressure Membrane Instrument by Soilmoisture Equipment Corp. Thermal conductivities for 12 soil moisture contents varying from saturation to dry were measured with the KD2 Thermal Properties Analyzer by Decagon Devices Inc. Additional information on the procedures adopted for the soil sampling and laboratory experiments can be found in Chen et al. (2012).

Table 2 lists the mean values for the soil texture ( $m_{\text {soc }}, \rho_{b}, \theta_{s}$, and $K_{s}$ ) found across the soil profile at the four SMST sites. The measurements demonstrate that the soils in the Maqu region are stratified, whereby in the upper layer a higher $m_{\text {soc }}$ is found, the percentage of sand typically increases with depth, and a substantial organic soil layer is found for the wetland ecosystems. This soil stratification can be associated with higher $\theta_{s}$ and $K_{s}$, while the $\rho_{b}$ is lower.

\section{Noah LSM}

The Noah LSM (Ek et al. 2003) is designed to form the land component of deterministic climate models, for example, the Weather Research and Forecasting (WRF) Model of the National Center for Atmospheric Research (NCAR), and is the LSM for which NASA makes the most extensive set of simulations available as part of the Global Land Data Assimilation System (GLDAS; Rodell et al. 2004). The model structure consists of a modestly complex canopy resistance scheme (Chen et al. 1996) linked to the diurnal Penman approach (Mahrt and Ek 1984) for simulating the latent heat flux and a surface energy balance approach whereby the entire soil-vegetation system is represented as a single heat and water vapor source. A four-layer soil scheme is implemented with the thermal diffusion equation for simulating heat transport 
TABLE 2. Average feature of soil properties measured by field and laboratory experiments in this study. From each depth we take three samples, and at some sites we find that at the same depth different soil properties, such as texture, are found, so we use a and b to highlight this.

\begin{tabular}{|c|c|c|c|c|c|c|c|c|}
\hline Site & Depth $(\mathrm{cm})$ & Sand (\%) & Clay (\%) & Texture & $m_{\text {soc }}(\%)$ & $\rho_{b}\left(\mathrm{~g} \mathrm{~cm}^{-3}\right)$ & $\theta_{s}\left(\mathrm{~m}^{3} \mathrm{~m}^{-3}\right)$ & $K_{s}\left(10^{-6} \mathrm{~m} \mathrm{~s}^{-1}\right)$ \\
\hline \multirow[t]{4}{*}{ CST01 } & $5-15$ & 34.78 & 9.38 & Silt loam & 2.78 & 1.05 & 0.55 & 1.18 \\
\hline & $20-40 a$ & 39.49 & 9.01 & Silt loam & 2.18 & 1.21 & 0.51 & 0.21 \\
\hline & $20-40 b$ & 65.56 & 5.45 & Sandy loam & 0.46 & 1.59 & 0.41 & \\
\hline & $55-70$ & 57.92 & 6.65 & Sandy loam & 0.51 & 1.56 & 0.42 & 0.04 \\
\hline \multirow[t]{3}{*}{ NST01 } & $5-15$ & 36.07 & 7.42 & Silt loam & 1.57 & 1.38 & 0.52 & 1.19 \\
\hline & $20-40$ & 52.33 & 6.65 & Sandy loam & 1.57 & 1.32 & 0.45 & 0.39 \\
\hline & $55-70$ & 61.24 & 5.92 & Sandy loam & 0.53 & 1.42 & 0.42 & 0.33 \\
\hline \multirow[t]{3}{*}{ NST04 } & $5-15$ & 36.57 & 7.10 & Organic soil & 18.25 & 0.50 & 0.76 & 2.15 \\
\hline & $20-40$ & 27.29 & 8.94 & Organic soil & 12.78 & 0.55 & 0.73 & 0.56 \\
\hline & $55-70$ & 18.24 & 9.42 & Silt loam & 6.28 & 0.97 & 0.64 & 0.19 \\
\hline \multirow[t]{4}{*}{ NST11 } & $5-15$ & 18.56 & 9.01 & Organic soil & 14.92 & 0.49 & 0.72 & 2.11 \\
\hline & $20-40$ & 30.17 & 11.01 & Silt loam & 3.45 & 1.05 & 0.59 & 0.41 \\
\hline & $55-70 a$ & 29.16 & 11.22 & Silt loam & 1.75 & 1.24 & 0.54 & 0.17 \\
\hline & $55-70 \mathrm{~b}$ & 48.05 & 6.01 & Sandy loam & 2.22 & 1.29 & 0.54 & \\
\hline
\end{tabular}

and the diffusivity form of Richards' equation for water flow (Mahrt and Pan 1984; Pan and Mahrt 1987). A simple water balance approach (Schaake et al. 1996) is adopted to simulate the surface runoff, and the cold season physics are implemented as described in Koren et al. (1999).

The model physics of Noah, version 3.4.1, associated with soil water flow are provided below, and the processes related to the soil heat transport and surface heat fluxes exchange are described in Part II. The readers are also referred to existing literature (e.g., Ek et al. 2003; Niu et al. 2011; van der Velde et al. 2009) for more additional information on the Noah LSM.

\section{a. Soil water flow}

The diffusivity form of Richards' equation is utilized by the Noah LSM for the simulation of soil water flow, which can be formulated as

$$
\frac{\partial \theta}{\partial t}=\frac{\partial}{\partial z}\left[D(\theta) \frac{\partial \theta}{\partial z}\right]+\frac{\partial K(\theta)}{\partial z}+S(\theta),
$$

where $\theta$ is the soil moisture content $\left(\mathrm{m}^{3} \mathrm{~m}^{-3}\right), t$ is the time (s), $D$ is the soil water diffusivity $\left(\mathrm{m}^{2} \mathrm{~s}^{-1}\right), K$ is the hydraulic conductivity $\left(\mathrm{ms}^{-1}\right), z$ is the soil depth $(\mathrm{m})$, and $S$ represents sources and sinks $\left[\mathrm{ms}^{-1}\right.$; i.e., precipitation and evapotranspiration (ET)]. The first term on the right-hand side of Eq. (1) defines the diffusive flow component driven by the vertical soil water potential $\psi$ gradient. The second term characterizes the convective flow mechanism forced by gravity. Through the gravity-induced convective flow, water is transported downward, whereas the diffusive flow mechanism may also transport water upward or downward depending on the direction of the $\psi$ gradient induced by the soil moisture profile. The latter ensures the ability to simulate capillary rise. The Noah soil model consists by default of a 2-m homogeneous soil column with four layers of $0.1,0.3,0.6$, and $1.0 \mathrm{~m}$ with increasing thickness toward the bottom.

Time integration of Eq. (1) is obtained via the implicit Crank-Nicolson finite difference scheme expressed for the Richards' equation as

$$
\begin{aligned}
\Delta z_{i} \frac{\theta_{i}^{n+1}-\theta_{i}^{n}}{\Delta t}= & D_{i}^{n+1} \frac{\theta_{i+1}^{n+1}-\theta_{i}^{n+1}}{z_{i+1}-z_{i}}-D_{i-1}^{n+1} \frac{\theta_{i}^{n+1}-\theta_{i-1}^{n+1}}{z_{i}-z_{i-1}} \\
& -\left(K_{i}^{n+1}-K_{i-1}^{n+1}\right)+\Delta z_{i} S_{i}
\end{aligned}
$$

where $n$ and $i$ represent the time and spatial step separately, $\Delta z$ represents the depth of the soil layer $(\mathrm{m})$, and $z$ represents the position of the midpoint of the soil layer $(\mathrm{m})$. Within Noah the implicit Crank-Nicolson finite difference scheme is solved using the tridiagonal matrix algorithm, which is applied twice for each time step that infiltration occurs.

\section{b. Soil hydraulic parameterization}

Both convective and diffusive flow mechanisms described in Eq. (1) are parameterized by the transport coefficients $K$ and $D$, which depend on the soil texture as well as soil moisture content. The empirical soil hydraulic scheme proposed by Campbell (1974) is utilized within the Noah LSM to parameterize the $\psi-\theta, K-\theta$, and $D-\theta$ relationships as a function of soil texture:

$$
\begin{aligned}
\psi(\theta) & =\psi_{s}\left(\theta / \theta_{s}\right)^{-b}, \\
K(\theta) & =K_{s}\left(\theta / \theta_{s}\right)^{2 b+3}, \\
D(\theta) & =D_{s}\left(\theta / \theta_{s}\right)^{b+2}, \quad \text { and } \\
D_{s} & =b K_{s}\left(\psi_{s} / \theta_{s}\right),
\end{aligned}
$$

where $\psi_{s}$ is the soil water potential at air entry $(\mathrm{m}), K_{s}$ $\left(\mathrm{m} \mathrm{s}^{-1}\right)$ and $\theta_{s}\left(\mathrm{~m}^{3} \mathrm{~m}^{-3}\right)$ are as previously defined, and 
$b$ is an empirical parameter (unitless) related to the pore size distribution of the soil matrix. The soil type-specific hydraulic parameters (i.e., $K_{s}, \theta_{s}, \psi_{s}$, and $b$ ) are obtained in Noah from the class pedotransfer function (PTF) provided in Cosby et al. (1984). Cosby et al. (1984) have also developed a continuous PTF for calculating the hydraulic parameters from particle size distribution data (e.g., fraction clay and sand), which is adopted by other LSMs, for instance, the Community Land Model (CLM). The continuous PTF from Cosby et al. is given in the appendix as well as the applicable class PTF for our study area.

\section{c. Root water uptake}

Root water uptake for evapotranspiration (including soil evaporation) is the main sink term of Eq. (1) responsible for the redistribution of water in the soil column. Total transpiration $E_{t}$ is allocated to each soil layer according to an effective root fraction $r_{e, i}$ :

$$
\begin{aligned}
& E_{t, i}= E_{t} r_{e, i}, \\
& r_{e, i}= \frac{f_{\mathrm{sw}_{i},} f_{\text {root }_{m}, i}}{n_{\text {root }}} f_{i=1} f_{\mathrm{sw}, i} f_{\text {root }_{m}, i} \\
& f_{\text {root }_{m}, i}= f_{\text {root }, i}+f_{\mathrm{sw}, i}-\frac{\sum_{i=1}^{n_{\text {root }}} f_{\mathrm{sw}, i}}{n_{\text {root }}}, \\
& f_{\mathrm{sw}, i}= \frac{\theta_{i}-\theta_{w}}{\theta_{c}-\theta_{w}}, \text { and } \\
& f_{\text {root }, i}= \frac{\Delta z_{i}}{n_{\text {root }}}, \\
& \sum_{i=1} \Delta z_{i}
\end{aligned}
$$

where $\Delta z_{i}$ is the depth of the $i$ th soil layer (m), $n_{\text {root }}$ is the total number of root layers (unitless), $\theta_{w}$ is the soil moisture content at wilting point $\left(\mathrm{m}^{3} \mathrm{~m}^{-3}\right), \theta_{c}$ is the critical soil moisture content $\left(\mathrm{m}^{3} \mathrm{~m}^{-3}\right)$ below which the simulated transpiration is reduced because of water stress, and $f_{\mathrm{sw}, i}$ $\left(f_{\text {root }, i}\right)$ is the soil water stress (root) fraction for the $i$ th soil layer. Note that the root distribution is assumed to be vertically uniform with the depth as weighing factor [Eq. (4e)]. Moreover, the modified root fraction $f_{\text {root }_{m}, i}$ represents the water stress compensation mechanism [Eq. (4c)], which implies that water stress in one part of the root zone can be compensated by enhanced water uptake from other moister parts ( $\mathrm{Li}$ et al. 2001).

\section{Augmentations to the Noah LSM}

\section{a. Consideration of organic matter}

Soil organic content (SOC) affects the structure as well as the physical properties of the soil and, thus, the effects of organic matter on the hydraulic properties need to be understood and taken into consideration. The approach utilized in this study is based on the additivity hypothesis (Federer et al. 1993; Lawrence and Slater 2008; Zeiliguer et al. 2000) that considers 1) each soil layer as a mixture of organic and mineral masses, 2) the bulk densities of soil organic matter $\rho_{b, \text { soc }}$ and mineral material $\rho_{b, \text { min }}$ constant in any mixture, and 3) the volume occupied by the organic $V_{t, \mathrm{soc}}$ and mineral $V_{t, \mathrm{~min}}$ fractions, as well as water retention to be additive.

Based on the above assumptions, the volumetric soil carbon or organic fraction of a soil layer $f_{t, \mathrm{soc}}$ can be defined as (Chen et al. 2012; Federer et al. 1993):

$$
\begin{aligned}
f_{t, \mathrm{soc}} & =\frac{V_{t, \mathrm{soc}}}{V_{t}}=m_{\mathrm{soc}} \frac{\rho_{b}}{\rho_{b, \mathrm{soc}}}, \\
\rho_{b} & =\frac{\rho_{b, \min } \rho_{b, \mathrm{soc}}}{m_{\mathrm{soc}} \rho_{b, \text { min }}+\left(1-m_{\mathrm{soc}}\right) \rho_{b, \mathrm{soc}}}, \text { and } \\
\rho_{b, \text { min }} & =\rho_{s, \text { min }}\left(1-\theta_{s, \text { min }}\right),
\end{aligned}
$$

where $V_{t}$ is the total volume of the soil layer $\left(\mathrm{m}^{3}\right) ; V_{t, \mathrm{soc}}$ $\left(\mathrm{m}^{3}\right), m_{\mathrm{soc}}\left(\mathrm{kg} \mathrm{kg}^{-1}\right), \rho_{b}\left(\mathrm{~kg} \mathrm{~m}^{-3}\right), \rho_{b, \mathrm{soc}}\left(\mathrm{kg} \mathrm{m}^{-3}\right)$, and $\rho_{b \text {, min }}$ $\left(\mathrm{kg} \mathrm{m}^{-3}\right)$ are as previously defined; and $\rho_{s, \min }$ and $\theta_{s, \min }$ are the particle density $\left(\mathrm{kg} \mathrm{m}^{-3}\right)$ and the porosity $\left(\mathrm{m}^{3} \mathrm{~m}^{-3}\right)$ of mineral matter. Herein, $\rho_{s, \min }$ and $\rho_{b, \text { soc }}$ are taken as $2700 \mathrm{~kg} \mathrm{~m}^{-3}$ (equivalent to a standard particle density of quartz; Peters-Lidard et al. 1998) and $130 \mathrm{~kg} \mathrm{~m}^{-3}$ (equivalent to a standard bulk density of peat; Lawrence and Slater 2008), respectively. Given $m_{\mathrm{soc}}, \rho_{b}$ and $f_{t, \mathrm{soc}}$ can be derived via the above equations. An alternative approach for estimating $\rho_{b}$ based on observed $m_{\text {soc }}$ has been developed for the Tibetan Plateau by Y09b and is formulated by

$$
\rho_{b}=0.3+1.28 \exp \left(-0.1724 m_{\mathrm{soc}}\right) .
$$

Following the additivity hypothesis, the soil hydraulic properties can be estimated as a weighted combination of values for the mineral and organic materials according to Lawrence and Slater (2008) as follows:

$$
\begin{aligned}
\theta_{s} & =\left(1-f_{t, \mathrm{soc}}\right) \theta_{s, \min }+f_{t, \mathrm{soc}} \theta_{s, \mathrm{soc}}, \\
\psi_{s} & =\left(1-f_{t, \mathrm{soc}}\right) \psi_{s, \min }+f_{t, \mathrm{soc}} \psi_{s, \mathrm{soc}}, \quad \text { and } \\
b & =\left(1-f_{t, \mathrm{soc}}\right) b_{\min }+f_{t, \mathrm{soc}} b_{\mathrm{soc}} .
\end{aligned}
$$

The hydraulic parameters of the mineral soil (i.e., $\theta_{s, \min }, \psi_{s, \min }$, and $b_{\min }$ ) can be obtained through a class or continuous PTF given by, for instance, Cosby et al. (1984), while the hydraulic properties of pure organic matter (i.e., $\theta_{s, \text { soc }}, \psi_{s, \text { soc }}$, and $b_{\text {soc }}$ ) depend on the state of decomposition as described in Letts et al. (2000). In addition to the Cosby et al. (1984) class and 
continuous PTFs, the appendix also provides the hydraulic properties for three organic soil types reported in Letts et al. (2000). The impact of organic matter on $K_{s}$ is considered via the Kozeny-Carman equation [Eq. (8)] as is described in the section below.

\section{b. Decrease of $K_{s}$ with depth}

Organic matter and living and decayed root systems affect the soil saturated hydraulic conductivity (Decharme et al. 2006), which can be very high near the surface and enlarge the hydraulic conductivity of the soil. On the other hand, the absence of organic material can reduce $K_{s}$ by as much as five orders of magnitude, specifically at deeper layers at $0.4-0.8 \mathrm{~m}$ where the soil particles are also more closely aligned (Letts et al. 2000). Beven (1982) proposed to estimate the observed decrease of $K_{s}$ with depth using an exponential relationship, which has been adopted by various LSMs (Chen and Kumar 2001; Decharme et al. 2006; Famiglietti and Wood 1994; Niu et al. 2011; Stieglitz et al. 1997).

The exponential profile of $K_{s}$ can be described as

$$
K_{s, z}=K_{s, r} e^{-f\left(z-d_{r}\right)}
$$

where $K_{s, r}$ is the reference saturated hydraulic conductivity $\left(\mathrm{m} \mathrm{s}^{-1}\right)$ at the reference depth $d_{r}(\mathrm{~m})$, while $K_{s, z}$ is the estimated saturated hydraulic conductivity $\left(\mathrm{m} \mathrm{s}^{-1}\right)$ at the soil depth $z(\mathrm{~m})$, and $f$ is the exponential profile decay factor $\left(\mathrm{m}^{-1}\right)$. This formulation can be transformed to a similar expression as introduced by Stieglitz et al. (1997) once $d_{r}$ is set to $0 \mathrm{~m}$, as well as into expressions comparable to the ones developed by Chen and Kumar (2001) and Decharme et al. (2006) if $d_{r}$ is set to the depth at which the compacted value $K_{s, r}$, provided in Clapp and Hornberger (1978), is reached. The Kozeny-Carman equation using both porosity and the slope $b$ of the water retention curve at the reference depth can be used to indirectly estimate $K_{s, r}$ as follows (Ahuja et al. 1984; Saxton and Rawls 2006):

$$
K_{s, r}=C\left(\theta_{s, r}-\theta_{33, r}\right)^{3-1 / b}
$$

where $\theta_{s, r}$ is the porosity $\left(\mathrm{m}^{3} \mathrm{~m}^{-3}\right)$ at the reference depth $d r(\mathrm{~m}), \theta_{33, r}$ is the water content $\left(\mathrm{m}^{3} \mathrm{~m}^{-3}\right)$ at $-33 \mathrm{kPa}$ matric potential at the reference depth, and $C$ is an empirically derived constant and herein taken as $1930 \mathrm{~mm} \mathrm{~h}^{-1}$ from Saxton and Rawls (2006). Besides the exponential function, the impact of organic matter on $K_{s}$ can also be indirectly accounted for by combining Eq. (8) with Eqs. (6a)-(6c).

The exponential profile decay factor in Eq. (7) can be estimated indirectly through calibration against measured streamflow recession curves or directly from in situ measurements that capture the $K_{s}$ decline as a function of depth (Chen and Kumar 2001). At large scales, the exponential profile decay factor is usually obtained via the first approach, and Niu et al. (2011) found that a value of $6 \mathrm{~m}^{-1}$ is appropriate for global applications based on calibration against streamflow measurements collected worldwide.

\section{c. Root distribution}

As described in section 3c, the Noah LSM assumes by default a uniform vertical distribution of the root across the soil profile. In reality, however, this is hardly ever the case. Especially for the Tibetan Plateau there have been reports (van der Velde et al. 2009; Yang et al. 2005) of a very dense distribution of roots in the top $10 \mathrm{~cm}$, whereas the roots are sparse in the deeper soil layers. Through the one-parameter asymptotic function proposed by Gale and Grigal (1987), such a vertical distribution of the roots can be considered as

$$
Y=1-\beta^{d},
$$

where $Y$ is the cumulative root fraction from the soil surface to depth $d(\mathrm{~cm})$ and $\beta$ is an empirical parameter (unitless). Jackson et al. (1996) estimated $\beta$ from the measured root distribution for each biome across the globe and for the Tibetan Plateau. Yang et al. (2009a) more recently reported values of 0.937 for alpine steppe and 0.900 for alpine meadow. The latter is applicable for our study area.

The uniform root distribution [Eq. (4e)] implemented in the current Noah LSM can be replaced with the above asymptotic function as follows:

$$
\begin{aligned}
f_{\text {root }, i} & =Y_{i}-Y_{i-1} \quad \text { and } \\
Y_{i} & =\left(1-\beta^{d, i}\right) /\left(1-\beta^{d, n_{\text {root }}}\right) .
\end{aligned}
$$

The total rooting depth can be defined as the depth at which the cumulative root fraction reaches an arbitrary value herein taken as $99 \%$ (Zeng 2001), and thus the total number of root layers as well as its vertical distribution are known.

\section{d. Modified soil water flow scheme implementation}

The current implementation of the diffusivity form of Richards' equation in Noah is not able to simulate water flow across a vertically heterogeneous soil profile. As such, the model code is first revised to enable the assignment of different hydraulic parameters for each soil layer. Specifically, the soil hydraulic parameters (i.e., $\theta_{s}, \psi_{s}$, and $b$ ) of each soil layer are calculated as the weighted combination of values for mineral and pure organic materials [Eqs. (6a)-(6c)], and the exponential profile of $K_{s}$ [Eq. (7)] is utilized as well.

Second, the implementation of Richards' equation is modified to mitigate the discontinuity in the soil water 
TABLE 3. Values of $R^{2}$, ME, and RMSE between measured and estimated $\rho_{b}$ and $\theta_{s}$ using the data collected around the Maqu station and the data from Chen et al. (2012).

\begin{tabular}{|c|c|c|c|c|c|c|c|}
\hline \multirow[b]{2}{*}{ Property } & \multirow[b]{2}{*}{ Method } & \multicolumn{3}{|c|}{ Maqu data } & \multicolumn{3}{|c|}{ Chen et al. data } \\
\hline & & $R^{2}$ & $\mathrm{ME}$ & RMSE & $R^{2}$ & $\mathrm{ME}$ & RMSE \\
\hline \multirow[t]{3}{*}{$\rho_{b}$} & $\mathrm{SOC}+$ class & 0.944 & $-0.021 \mathrm{~g} \mathrm{~cm}^{-3}$ & $0.099 \mathrm{~g} \mathrm{~cm}^{-3}$ & 0.893 & $-0.016 \mathrm{~g} \mathrm{~cm}^{-3}$ & $0.199 \mathrm{~g} \mathrm{~cm}^{-3}$ \\
\hline & SOC + continuous & 0.943 & $0.012 \mathrm{~g} \mathrm{~cm}^{-3}$ & $0.093 \mathrm{~g} \mathrm{~cm}^{-3}$ & 0.914 & $-0.001 \mathrm{~g} \mathrm{~cm}^{-3}$ & $0.189 \mathrm{~g} \mathrm{~cm}^{-3}$ \\
\hline & Y09b & 0.943 & $-0.073 \mathrm{~g} \mathrm{~cm}^{-3}$ & $0.122 \mathrm{~g} \mathrm{~cm}^{-3}$ & 0.924 & $-0.134 \mathrm{~g} \mathrm{~cm}^{-3}$ & $0.215 \mathrm{~g} \mathrm{~cm}^{-3}$ \\
\hline \multirow[t]{4}{*}{$\theta_{s}$} & Class PTF & 0.553 & $-0.105 \mathrm{~m}^{3} \mathrm{~m}^{-3}$ & $0.148 \mathrm{~m}^{3} \mathrm{~m}^{-3}$ & 0.363 & $-0.118 \mathrm{~m}^{3} \mathrm{~m}^{-3}$ & $0.180 \mathrm{~m}^{3} \mathrm{~m}^{-3}$ \\
\hline & Continuous PTF & 0.607 & $-0.127 \mathrm{~m}^{3} \mathrm{~m}^{-3}$ & $0.164 \mathrm{~m}^{3} \mathrm{~m}^{-3}$ & 0.281 & $-0.133 \mathrm{~m}^{3} \mathrm{~m}^{-3}$ & $0.196 \mathrm{~m}^{3} \mathrm{~m}^{-3}$ \\
\hline & SOC + class & 0.973 & $0.004 \mathrm{~m}^{3} \mathrm{~m}^{-3}$ & $0.030 \mathrm{~m}^{3} \mathrm{~m}^{-3}$ & 0.932 & $0.005 \mathrm{~m}^{3} \mathrm{~m}^{-3}$ & $0.068 \mathrm{~m}^{3} \mathrm{~m}^{-3}$ \\
\hline & SOC + continuous & 0.971 & $-0.009 \mathrm{~m}^{3} \mathrm{~m}^{-3}$ & $0.028 \mathrm{~m}^{3} \mathrm{~m}^{-3}$ & 0.916 & $0.011 \mathrm{~m}^{3} \mathrm{~m}^{-3}$ & $0.066 \mathrm{~m}^{3} \mathrm{~m}^{-3}$ \\
\hline
\end{tabular}

content at the interface of two soil layers with different hydraulic properties. This is accomplished via the solution provided by Hills et al. (1989) through adding a term to the Crank-Nicolson scheme:

$$
\begin{aligned}
\Delta z_{i} \frac{\theta_{i}^{n+1}-\theta_{i}^{n}}{\Delta t}= & D_{i}^{n+1} \frac{\theta_{i+1}^{n+1}-\theta_{i}^{n+1}}{z_{i+1}-z_{i}}-D_{i-1}^{n+1} \frac{\theta_{i}^{n+1}-\theta_{i-1}^{n+1}}{z_{i}-z_{i-1}} \\
& -\left(K_{i}^{n+1}-K_{i-1}^{n+1}\right)+\Delta z_{i} S_{i} \\
& -\left(D_{i}^{n+1} \frac{\Delta \theta_{a, i}^{n+1}}{z_{i+1}-z_{i}}-D_{i-1}^{n+1} \frac{\Delta \theta_{a, i-1}^{n+1}}{z_{i}-z_{i-1}}\right)
\end{aligned}
$$

where $\Delta \theta_{a}$ is introduced to account for the discontinuity in the soil water content across the interface of two soil layers, defined as

$$
\Delta \theta_{a, i}=\theta_{s, i}\left(\psi_{a, i} / \psi_{s, i}\right)^{-1 / b_{i}}-\theta_{s, i+1}\left(\psi_{a, i} / \psi_{s, i+1}\right)^{-1 / b_{i+1}},
$$

where $\psi_{a}$ is the soil water potential at the interface and can be estimated as

$\psi_{a, i}=\frac{\left(K_{i}-K_{i+1}\right)+2 K_{i} \psi_{i} / \Delta z_{i}+2 K_{i+1} \psi_{i+1} / \Delta z_{i+1}}{2 K_{i} / \Delta z_{i}+2 K_{i+1} / \Delta z_{i+1}}$.

\section{Estimation of soil hydraulic properties}

\section{a. Bulk density and porosity}

From section 4 three methods can be deduced for calculating $\rho_{b}$ based on the measured $m_{\text {soc }}$ : using Eqs. (5b) and (5c) with $\theta_{s, \min }$ adopted from either Cosby's 1) class (SOC+class) or 2) continuous PTF (SOC + continuous), and 3) the empirical approach proposed by Y09b [Eq. (5d)]. The porosity can be estimated by Cosby's 1) class and 2) continuous PTF disregarding the contribution of organic matter content. On the other hand, the impact of organic matter on $\theta_{s}$ can also be accounted for via Eq. (6a) with the $\theta_{s, \min }$ adopted from either Cosby's 3) class (SOC + class) or 4$)$ continuous PTF (SOC+continuous), and the porosity of an organic soil given in Letts et al. (2000), which is taken equal to $0.83 \mathrm{~m}^{3} \mathrm{~m}^{-3}$ because of the similarity between the soil water retention curve of organic soil in this study and that for sapric peat (to be shown in the following section). The value of $f_{t, \text { soc }}$ in Eq. (6a) is estimated by Eqs. (5a)-(5c) based on the measured $m_{\mathrm{soc}}$.

In this study, we apply the methods for estimating the $\theta_{s}$ and $\rho_{b}$ to two soil property datasets collected across the Tibetan Plateau. The first is based on the measurements around the Maqu station described in section $2 b$, and the second is reported in Chen et al. (2012), consisting of samples from four sites situated in the central and eastern parts of the plateau. Table 3 gives the error statistics following from the comparison of the measured and estimated $\rho_{b}$ and $\theta_{s}$, that is, the coefficient of determination $R^{2}$, mean error (ME), and root-meansquare error (RMSE). With $R^{2}$ values larger than 0.89 , the error statistics indicate that all three methods are capable of providing reasonable $\rho_{b}$ estimates. Although with the $\rho_{b}$ estimates obtained via Y09b, comparable or better $R^{2}$ values are obtained, the ME and RMSE achieved with the methods proposed in this study are significantly lower, on an absolute average 0.013 versus $0.104 \mathrm{~g} \mathrm{~cm}^{-3}$ for the ME and 0.145 versus $0.169 \mathrm{~g} \mathrm{~cm}^{-3}$ for the RMSE. In this regard, the continuous PTF performs slightly better than the class PTF. Apparently, the reliability of $\rho_{b}$ estimates benefits from the within-class variability embedded within the continuous PTF.

The error statistics associated with the $\theta_{s}$ determination reveal a somewhat mixed performance. The $\theta_{s}$ estimates produced with the standard Cosby's class and continuous PTFs yield an $R^{2}$ ranging from 0.281 to 0.607 and RMSE values as high as $0.196 \mathrm{~m}^{3} \mathrm{~m}^{-3}$. However, with consideration of the soil organic content via the additivity approach, this improves significantly with an $R^{2}$ better than 0.915 and an RMSE varying from 0.028 to $0.068 \mathrm{~m}^{3} \mathrm{~m}^{-3}$. To investigate this further, Table 4 provides correlation coefficients calculated among $\theta_{s}\left(\mathrm{~m}^{3} \mathrm{~m}^{-3}\right), \rho_{b}\left(\mathrm{~g} \mathrm{~cm}^{-3}\right)$, and $m_{\mathrm{soc}}(\%)$, as well as soil texture [i.e., percentage of sand, clay, and silt (\%)] for both soil datasets combined. 
TABLE 4. Correlation coefficients calculated among $\theta_{s}, \rho_{b}, m_{\mathrm{soc}}$, and soil particle size distribution.

\begin{tabular}{rcccrrr}
\hline & $\theta_{s}$ & $\rho_{b}$ & $m_{\text {soc }}$ & Sand & Clay & Silt \\
\hline$\theta_{s}$ & - & -0.932 & 0.754 & -0.340 & 0.385 \\
$\rho_{b}$ & -0.932 & - & -0.775 & 0.273 & -0.051 & -0.317 \\
\hline
\end{tabular}

The $\theta_{s}$ and $\rho_{b}$ clearly have a much stronger relationship with $m_{\text {soc }}$ than other soil texture components. This explains why the Cosby's PTFs with explicit consideration of organic matter outperforms the standard approach. Hence, it can be concluded from this analysis that including the $m_{\mathrm{soc}}$ within a PTF is imperative for providing a robust $\theta_{s}$ estimate, at least for Tibetan soils.

\section{b. Soil water retention curve}

Figure 2 shows the soil water retention measurements for the three soil types (organic soil, silt loam, and sandy loam) as well as estimates of the retention curve with Campbell's soil hydraulic model [Eq. (3a)]. Specifically, the soil data given in Table 2 are regrouped by soil texture. Comparable to the previous section, the hydraulic parameters (e.g., $\theta_{s}, \psi_{s}$, and $b$ ) are for both organic and mineral soils deduced from Cosby's class and continuous PTFs with and without consideration of the $m_{\mathrm{soc}}$ as described in section 4a. Again, the sapric peat parameterization reported in Letts et al. (2000) is adopted to represent the hydraulic characteristics of pure organic matter. It should be noted that for clarity Fig. 2a for the organic soils shows the retention curve produced with only Letts's sapric peat parameterization instead of the two curves obtained with Cosby's class and continuous PTFs. It shows that the retention curve for the organic soils in this study is comparable to that for sapric peat.

Table 5 lists for each soil type the mean $m_{\mathrm{soc}}$ and percentages of sand, clay, and silt, as well as the RMSE computed between the measured and estimated soil water content. This table shows that the $m_{\mathrm{soc}}$ of sandy loam soils is much lower than for the other two types, which can be attributed to the fact that the sandy loam soils in the Maqu region are mostly present in deeper layers (see Table 2). The RMSEs reported in Table 5 as well as Fig. 2 highlight that the Cosby class PTF with consideration of organic matter (SOC+class) provides the best estimates of the soil water retention measurements from the organic and silt loam soils. The obtained RMSEs are 0.034 and $0.027 \mathrm{~m}^{-3} \mathrm{~m}^{-3}$ for the organic and silt loam soils, respectively, versus RMSEs of 0.090 and $0.078 \mathrm{~m}^{-3} \mathrm{~m}^{-3}$ for the organic and silt loam soils, respectively, achieved with the SOC + continuous parameterization as the runner up.

In contrast to the $\rho_{b}$ results, the $\mathrm{SOC}+$ class parameterization outperforms the $\mathrm{SOC}+$ continuous estimates of the retention curve. Apparently, the empirical shape parameter and the $\psi_{s}$ provided by Cosby's continuous PTF are less representative for the organic and silt loam soils studied here. This is confirmed by the large RMSEs obtained with the continuous parameterization in comparison to the results with the class parameterization. On the other hand, better results are achieved with Cosby's continuous PTF for the sandy loam soils, for which the inclusion of $m_{\mathrm{soc}}$ in the estimation of the retention curve also somewhat reduces its accuracy. This suggests that consideration of $m_{\text {soc }}$ for estimation of the retention curve is only beneficial if the soil includes a significant amount of organic matter. Otherwise, uncertainties following from inaccuracies in the $m_{\mathrm{soc}}$ determination become relatively large.
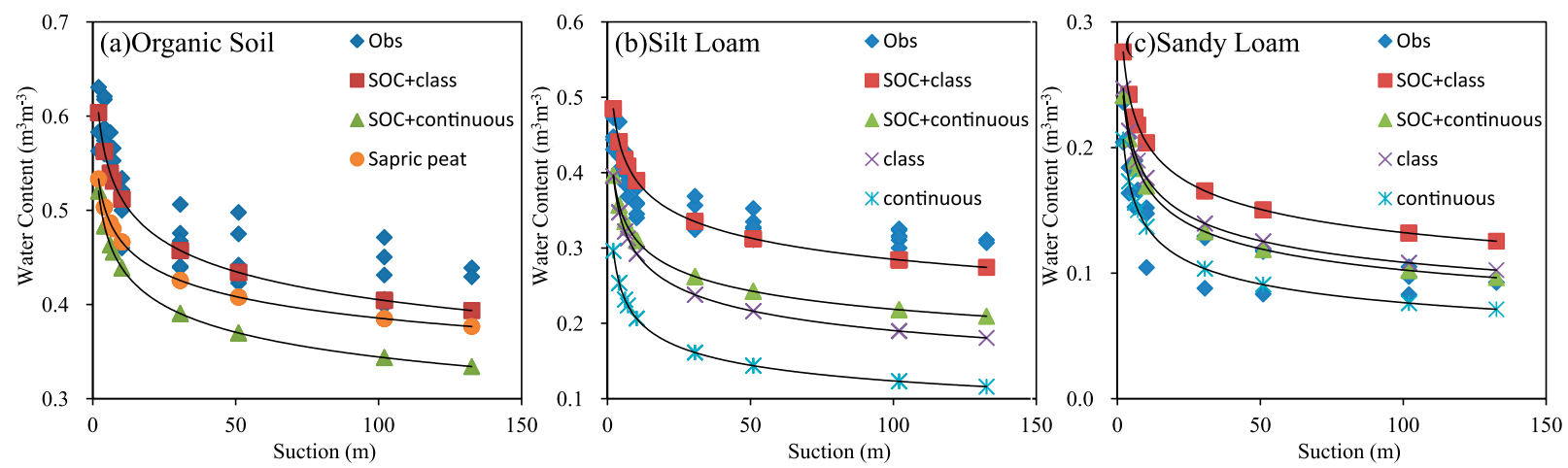

FIG. 2. Comparison of the observed and estimated soil water retention curves for (a) organic soil, (b) silt loam, and (c) sandy loam deduced from Cosby's class or continuous PTF without and with consideration of the SOC. 
TABLE 5. Average feature of soil properties regrouped by soil type, as well as RMSE between measured and estimated soil water contents associated with different pressure heads.

\begin{tabular}{lccccccc}
\hline \hline & & & & \multicolumn{3}{c}{ RMSE $\left(\mathrm{m}^{3} \mathrm{~m}^{-3}\right)$} \\
\cline { 6 - 8 } Soil type & $m_{\text {soc }}(\%)$ & Sand $(\%)$ & Clay $(\%)$ & Class & Continuous & SOC+class & SOC+continuous \\
\hline Organic soil & 15.31 & 27.47 & 8.35 & 0.232 & 0.316 & 0.034 & 0.090 \\
Silt loam & 3.44 & 30.12 & 9.70 & 0.097 & 0.176 & 0.027 & 0.078 \\
Sandy loam & 0.70 & 58.13 & 6.36 & 0.031 & 0.022 & 0.055 & 0.026 \\
\hline
\end{tabular}

\section{c. Saturated hydraulic conductivity}

Figure 3 shows the in situ saturated hydraulic conductivity measurements as a function of soil depth carried out around the four SMST sites. In addition, $K_{s}$-soil depth relationships are plotted that are estimated with the approach of Beven (1982) [see Eq. (7) in section 4], whereby the exponential decay factor is taken equal to $6 \mathrm{~m}^{-1}$, as suggested by Niu et al. (2011). The required reference saturated hydraulic conductivity is estimated here using Cosby's 1) class or 2) continuous PTF with the reference depth set at $0.05 \mathrm{~m}$ (i.e., the midpoint of the first layer in the Noah LSM), as well as via 3) the Kozeny-Carman equation [Eq. (8)] with the unknown hydraulic parameters adopted from
Cosby's class PTF with consideration of organic matter as described in section $4 \mathrm{~b}$.

The measurements indicate that, in general, the $K_{s}$ decreases by one to two orders of magnitude over a soil depth from 0.15 to $0.6 \mathrm{~m}$. The reason for this is that organic matter and plant roots are abundant in the upper soil layers (see Table 2), affecting the soil aggregation and associated pore space distribution that leads to higher water holding capacity and conductivity compared with lower soil layers. Further, it should be noted that the $K_{s}$ values for the two wetland sites (NST04 and NST11) are comparable to the other two grassland sites, which suggests that a higher $m_{\text {soc }}$ does not necessarily imply a larger $K_{s}$. This is in agreement with earlier findings by, for instance, Nemes et al. (2005), who
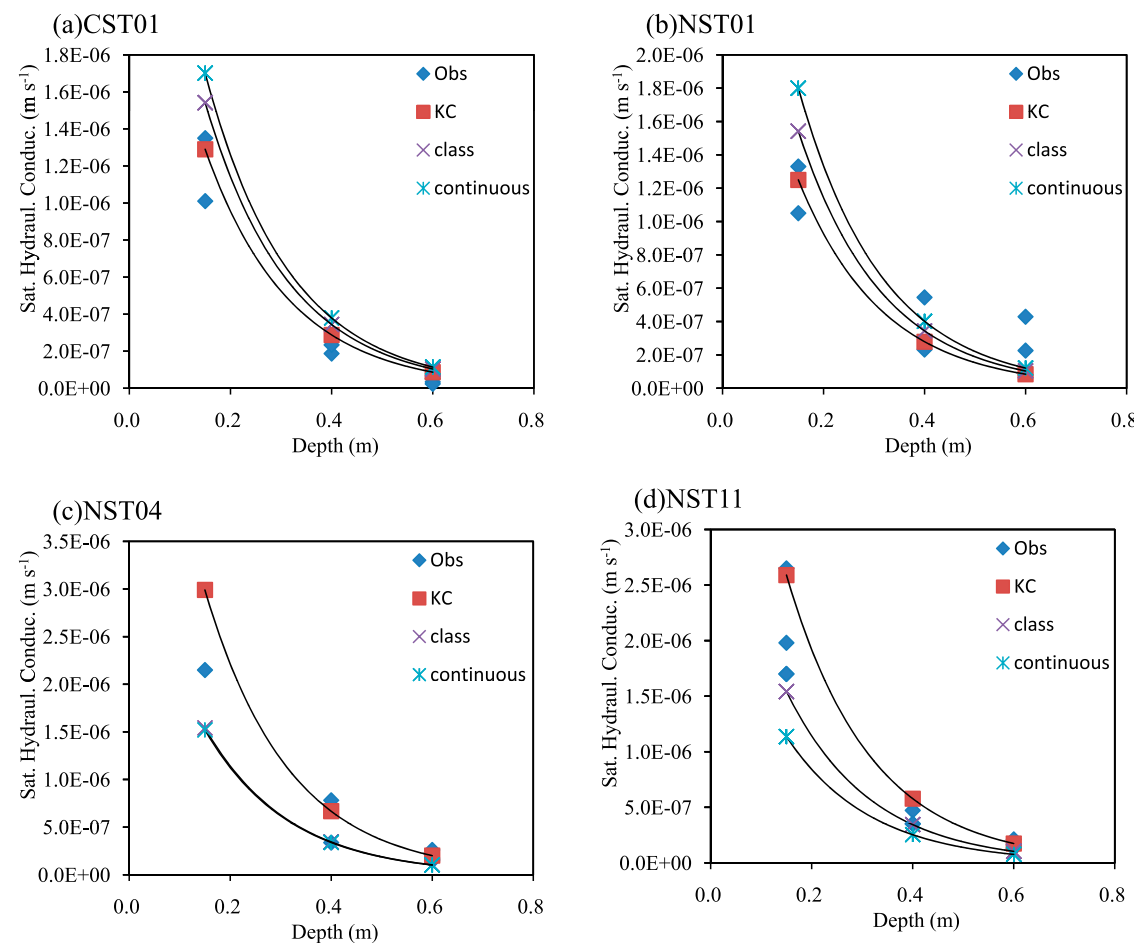

FIG. 3. Comparison of the observed and estimated saturated hydraulic conductivity as an exponential function of soil depth carried out for four SMST sites. The legend indicates laboratory measurements (Obs) and estimates obtained with the Kozeny-Carman equation (KC), Cosby's class (class), and the continuous PTF (continuous). 
concluded that organic matter retains water well, which limits the hydraulic conductivity. Moreover, according to Carey et al. (2007), $K_{s}$ is typically constrained by the pore segments with the smallest diameter that may form only a small fraction of the total pore size distribution of organic soils.

The implementation of Beven's approach for describing $K_{s}$ is a function of the soil depth whereby the reference saturated hydraulic conductivity is estimated by the Kozeny-Carman equation. The most notable differences are obtained near the soil surface where $K_{s}$ is largest and, thus, the flow of water through the soil is largest. The implementations of Cosby's class and continuous PTFs typically overestimate $K_{s}$ for the mineral soils (CST01 and NST01) while they underestimate $K_{s}$ for the organic soil wetland sites (NST04 and NST11). However, it should be noted that the Kozeny-Carman estimate of $K_{s}$ for the wetland NST04 site overestimates the measurements, but falls within the measured $K_{s}$ range for the other wetland site (NST11).

\section{Simulation of soil moisture with the Noah LSM}

\section{a. Design of numerical experiments}

Three experiments are designed to assess the impact of the augmentations to the default Noah LSM described in section 4. A control experiment (Ctrl) is performed first by running the Noah LSM with the default soil hydraulic and root uptake scheme as described in section 3. Second, the default hydraulic scheme is replaced with the soil organic scheme (see section 5) and the modified diffusivity form of Richards' equation [Eq. (11)] that resolves the soil moisture discontinuity at the interface of two layers (EXP1; see section 4d). Third, the distribution of roots in the soil profile is implemented as a function of depth following Eqs. (10a) and (10b) instead of the default uniform distribution (EXP2). It should be noted that the augmentations to the surface heat fluxes exchange and soil heat transport described in Part II are implemented by the three experiments.

All the experiments are forced by the meteorological measurements collected at the PBL tower from 8 June to 30 September 2010 and include air temperature, relative humidity, wind speed, air pressure, upward and downward shortwave radiations, downward longwave radiation, and precipitation (see Table 1). The observation height of the air temperature and wind speed is $2.35 \mathrm{~m}$. The prescribed vegetation type is grassland, and the monthly values of green vegetation fraction $(\mathrm{GVF})$ and leaf area index (LAI) are derived from the Système Pour l'Observation de la Terre (SPOT) 10 daily synthesis NDVI product as in Zheng et al. (2014). The other vegetation parameters (e.g., number of root layers) are obtained from Noah's default land-cover database. The $\beta$ for EXP2 is taken as the value (0.900) for the alpine meadow reported in Yang et al. (2009a), and then the number of root layers is computed using the method described in section $4 \mathrm{c}$.

The silt loam is adopted as soil texture according to measured properties (see Table 2) found at the upper layers of the two SMST sites (CST01 and NST01) near the PBL tower. Corresponding hydraulic parameters for Ctrl are obtained using Cosby's class PTF. The $m_{\mathrm{soc}}$ of each soil layer for EXP1 and EXP2 is taken as the average of the value derived from measurements collected at the CST01 and NST01 sites, and sapric peat data from Letts et al. (2000) are adopted to represent the hydraulic parameters for pure organic matter. Beven's approach for describing $K_{s}$ as a function of soil depth is implemented by EXP1 and EXP2, and the reference saturated hydraulic conductivity is estimated via the Kozeny-Carman equation [Eq. (8); see section $5 \mathrm{c}]$. Further, it should be noted that the $K_{s}$ value of the bottom (fourth) layer is set equal to that for the third layer as the decrease of $K_{s}$ with depth is limited for the deep layers. Similarly, the $m_{\text {soc }}$ value of the bottom layer is set equal to that for the third layer as well.

Soil moisture and temperature measurements are used to initialize each model run as well as to validate Noah simulations. For both, the measurements collected at sites CST01 and NST01 are averaged for each soil depth (e.g., $0.05,0.10,0.20,0.40$, and $0.80 \mathrm{~m}$ ) and subsequently interpolated to the midpoints of the upper three model layers (i.e., $0.05,0.25$, and $0.70 \mathrm{~m}$ ). Then, the soil moisture and temperature of the fourth layer is taken for initialization equal to the states of the third layer. The Noah simulations are further validated through comparisons of the simulated sensible and latent heat fluxes with measurements collected by an EC system.

\section{b. Noah soil moisture simulations}

Figure 4 shows time series with a 30-min interval of the measured soil moisture and the simulations produced by the previously described three numerical experiments along with the measured rainfall. Figures $4 a-c$ provide the measurements and simulations for soil depths of 5, 25, and $70 \mathrm{~cm}$, respectively. Three distinct dry-down episodes (periods in which soil moisture gradually depletes) can be deduced from Fig. 4a, for example, 1) days of year (DOY) 159-179, 2) DOY 204224, and 3) DOY 244-264 with corresponding wetting periods (i.e., DOY 179-204, 224-244, and 264 onward). The default configuration of the Noah LSM (Ctrl) tends to underestimate the soil moisture, especially for the two upper soil layers. For the top layer the soil moisture underestimation is most notable under wet conditions, 

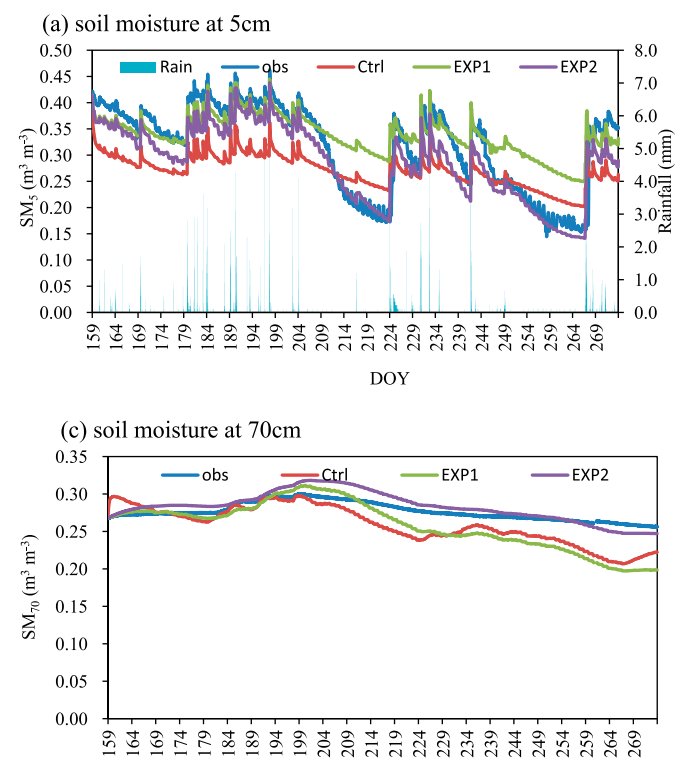

DOY

while below a soil moisture content of $0.25 \mathrm{~m}^{3} \mathrm{~m}^{-3}$ the underestimation changes into an overestimation.

The inability to accurately simulate the surface soil moisture over the Tibetan Plateau has also been recently reported for other LSMs (Chen et al. 2013; Su et al. 2013; Xue et al. 2013). Yang et al. (2005) and Chen et al. (2013) attributed this to the absence of a soil stratification linked specifically to organic matter within model structures. Indeed, the underestimation of surface soil moisture significantly improved during the wetting periods after implementing the soil organic scheme (EXP1). The explanation for this is that the relative abundance of organic matter in the upper layers leads to a larger soil porosity and higher water holding capacity. Consequently, the EXP1 simulation tends to retain water in the upper layers, which causes an overestimation of soil moisture in the upper layers during dry-downs. This is further enhanced by the exponential $K_{s}$ decay as a function of depth, which reduces the convective and diffusive flow components toward the deeper layer via the transport coefficients $K$ and $D$ and suppresses the redistributed soil water across soil layers (Braun and Schädler 2005).

As such, the augmentations implemented for EXP1 enable the Noah model to better simulate the soil moisture content during wet episodes, but it does not lead to an improvement for the dry-downs. The soil moisture results following from the EXP2 simulation show that this can be associated with the default uniform root distribution implemented in Noah. This assumed that the root fraction in each layer is proportional to the layer thickness, which leads to more root uptake from the deeper (lower) soil layers. In reality, however, the majority of the

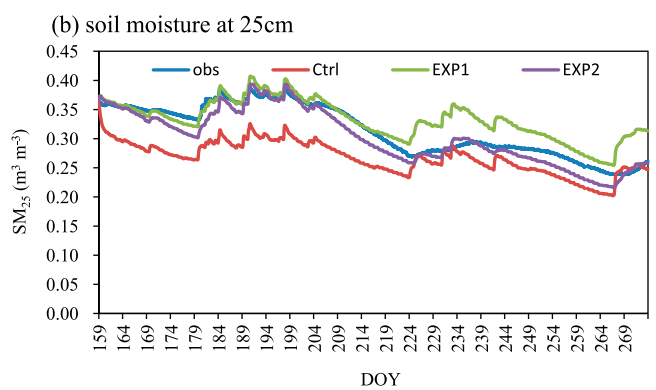

FIG. 4. Comparison of the observed and simulated soil moisture produced by three Noah numerical experiments for each soil layer from 8 Jun to $30 \mathrm{Sep}$ 2010: (a) $5 \mathrm{~cm}$, (b) $25 \mathrm{~cm}$, and (c) $70 \mathrm{~cm}$.

plant roots are located in the upper soil layer of Tibetan ecosystems (Yang et al. 2009a). Hence, both Ctrl and EXP1 overestimate the soil moisture content of the upper soil layers during dry-downs (i.e., 0.05 and $0.25 \mathrm{~m}$ ) and underestimate it for the lower soil layers (i.e., $0.70 \mathrm{~m}$ ). Implementation of the root distribution as an asymptotic function of depth [Eqs. (10a), (10b)] allows Noah (EXP2) to take up more water for transpiration from the upper soil layers. This modification to the model structure also enables the soil moisture simulations to better capture the dynamics measured at each soil depth under dry-down conditions, as can be seen in Fig. 4.

Table 6 gives the error statistics (i.e., $R^{2}, \mathrm{ME}$, and RMSE) between the measured and simulated soil moisture produced by the three experiments. The error statistics confirm improvement in the soil moisture simulation achieved by EXP1 and EXP2 model runs in comparison to Ctrl. The $R^{2}$ calculated for the difference between the measurements and simulations increased on average for the three soil depths $(0.05,0.25$, and $0.70 \mathrm{~m})$ from 0.73 for Ctrl to 0.8 for EXP1 to 0.93 for EXP2. This clearly highlights that the EXP2 simulations are superior in capturing the soil moisture dynamics. This is further supported by reductions in the ME by about $39 \%, 77 \%$, and $61 \%$ and RMSE by $49 \%, 70 \%$, and $56 \%$ in comparison to the $\mathrm{Ctrl}$ error statistics for the three soil depths, respectively.

\section{Discussion}

\section{a. Impact on surface energy budget simulations}

Soil moisture plays an important role in the energy balance by controlling the partition of the surface 
TABLE 6. Error statistics computed between measured and simulated soil moisture produced by three Noah numerical experiments from 8 Jun to 30 Sep 2010.

\begin{tabular}{|c|c|c|c|c|c|c|c|c|c|}
\hline \multirow[b]{2}{*}{ Expt } & \multicolumn{3}{|c|}{$\mathrm{SM}_{5}$} & \multicolumn{3}{|c|}{$\mathrm{SM}_{25}$} & \multicolumn{3}{|c|}{$\mathrm{SM}_{70}$} \\
\hline & $R^{2}$ & $\operatorname{ME}\left(\mathrm{m}^{3} \mathrm{~m}^{-3}\right)$ & $\operatorname{RMSE}\left(\mathrm{m}^{3} \mathrm{~m}^{-3}\right)$ & $R^{2}$ & $\operatorname{ME}\left(\mathrm{m}^{3} \mathrm{~m}^{-3}\right)$ & $\operatorname{RMSE}\left(\mathrm{m}^{3} \mathrm{~m}^{-3}\right)$ & $R^{2}$ & $\operatorname{ME}\left(\mathrm{m}^{3} \mathrm{~m}^{-3}\right)$ & $\operatorname{RMSE}\left(\mathrm{m}^{3} \mathrm{~m}^{-3}\right)$ \\
\hline Ctrl & 0.795 & -0.046 & 0.074 & 0.767 & -0.047 & 0.053 & 0.612 & -0.018 & 0.025 \\
\hline EXP1 & 0.805 & 0.021 & 0.056 & 0.759 & 0.019 & 0.029 & 0.836 & -0.018 & 0.028 \\
\hline EXP2 & 0.923 & -0.028 & 0.038 & 0.941 & -0.011 & 0.016 & 0.917 & 0.007 & 0.011 \\
\hline
\end{tabular}

energy budget into the sensible and latent heat fluxes. Below critical soil moisture levels, evaporation is suboptimal and the radiation excess is converted into heat. Soil moisture also affects the soil heat conductivity and the soil heat capacity that influences the transport of heat $G_{0}$ into the soil. The accuracy of the simulated soil moisture will, therefore, inevitably have an impact on the simulations of the heat fluxes and soil temperatures.

Figure 5 shows the partitioning of the surface energy budget into LE, $H$, and $G_{0}$ produced by the three Noah runs (Ctrl, EXP1, and EXP2) presented as a ratio of the net radiation $R_{n}$, whereby the heat fluxes are accumulated over the entire study period. In general, LE is the dominant component of the surface energy budget for the selected simulation period and little difference is noted in the energy partitioning between the three Noah runs. To support the analysis, Fig. 6 shows the mean diurnal cycle of the measured and simulated sensible and latent heat fluxes for June-September, which confirms the minor impact of soil water flow physics on the simulated surface heat flux. The reason for this is that the LE in the selected study area is primarily driven by the available energy during the wet monsoon season. Hence, all three numerical experiments generate soil moisture profiles that sustain the production of nonwater-limited LE, while performing significantly differently in redistributing the total transpiration and soil water extraction across the soil profile (see Fig. 4). Nevertheless, it is noted that the measured $H$ is overestimated by $\sim 20-40 \mathrm{~W} \mathrm{~m}^{-2}$ during midday for each of the three Noah runs, whereas fairly small systematic differences are observed between the simulated and measured LE.

Table 7 gives the error statistics (i.e., RMSE and ME) computed between the measured and simulated heat fluxes (e.g., LE and $H$ ) and soil temperature (e.g., surface and $25 \mathrm{~cm}$ ) for the study period at a $30-\mathrm{min}$ time step. Overall, the statistics indicate that the heat fluxes produced by Noah are reasonable (also shown in Fig. 6) with RMSE values for $\mathrm{LE}$ on the order of $30 \mathrm{~W} \mathrm{~m}^{-2}$ and confirm small differences among the three numerical experiments. It should, however, be noted that Noah somewhat overestimates heat fluxes and soil temperature, which can be associated with the energy closure problem of EC observations as described in Zheng et al. (2014). Moreover, the RMSE computed for the heat fluxes (i.e., $H$ and LE) increased upon implementation of each set of augmentations, from Ctrl to EXP1 to EXP2, because less LE and more $H$ and $G_{0}$ is produced (see Fig. 5). This can be attributed to the definitions of wilting and critical soil moisture as well as the vegetation parameters that control the soil water stress imposed on the soil evaporation and vegetation transpiration within Noah. Indeed, van der Velde et al. (2009) have shown that through modification of the vegetation parameterization, large improvements can be obtained in the simulation of the heat fluxes and particularly LE. However, further work is needed to assess the suitability of Noah's LE parameterization for the Tibetan Plateau ecosystems.

\section{b. Impact on surface water budget simulations}

Apart from its influence on the surface energy balance, soil moisture also has an effect on the simulated water budget by 1) determining the rainfall-runoff response through partitioning of precipitation into surface runoff and infiltration, 2) defining the drainage through the soil column toward deeper layers, and 3) limiting the evapotranspiration in cases of soil water stress (see the previous section). The impact of the augmentations made to the Noah model structure on the simulated water budget is illustrated by Fig. 7, in which the ratios of the different water budget components are shown. These ratios are calculated

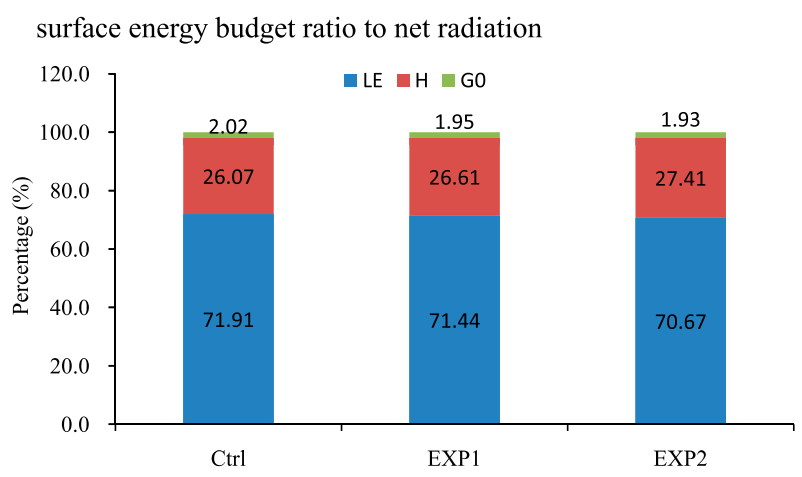

FIG. 5. Partitioning of the surface energy budget into LE, $H$, and $G_{0}$ produced by three Noah numerical experiments (Ctrl, EXP1, and EXP2) presented as a ratio of the net radiation accumulated from 8 Jun to 30 Sep 2010. 
(a)latent heat flux

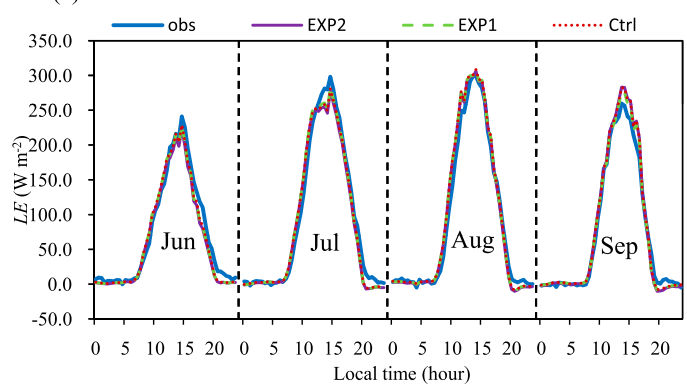

(b)sensible heat flux

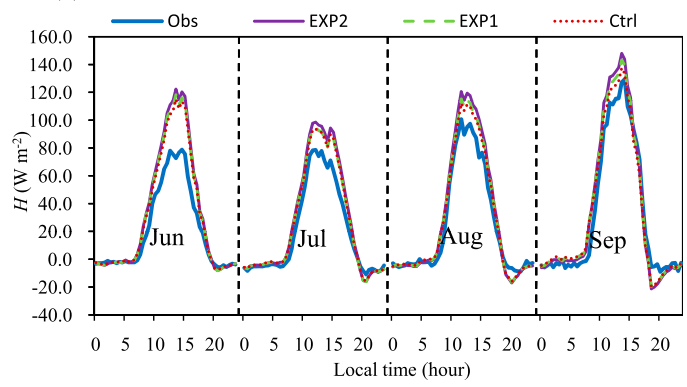

FIG. 6. Average diurnal cycles for June-September of the measured and simulated (a) LE and (b) $H$ produced by three Noah numerical experiments (Ctrl, EXP1, and EXP2).

by dividing the total simulated ET, $R_{\text {surf, drainage, and }}$ change in soil water storage $(\Delta \mathrm{SM})$ by the total rainfall measured from 8 June to 30 September 2010.

Figure 7 shows in analogy with the simulated surface energy budgets (Fig. 5) that all three Noah runs produce comparable water budgets and that ET is the dominant contribution. In comparison with the Ctrl run, Noah partitions less solar energy into ET (or LE) with the EXP2 setup. This leads to less water being extracted from the soil for evapotranspiration (i.e., lower ratio of ET), which explains the higher $\triangle \mathrm{SM}$ for EXP1 and, to a lesser extent, EXP2. Further, the implementation of the exponentially decaying $K_{s}$ with depth (i.e., EXP1 and EXP2) reduces the drainage component. Also, the $R_{\text {surf }}$ is lower for EXP1 and EXP2, which can be attributed to the consideration of organic matter that increases the water holding capacity of the soil. In summary, the modifications made to the Noah model structure lead to more water retained in the soil column at the expense of the other water balance components (e.g., ET, $R_{\text {surf }}$, and drainage).

\section{Conclusions}

This is the first of two papers aimed at diagnosing and enhancing the performance of the Noah land surface model (LSM) in simulating surface water and energy budgets in the high-altitude source region of the Yellow River (SRYR). In this paper, we investigate the ability of the Noah LSM to simulate the soil water flow through comparison with soil moisture profiles measured during the monsoon season. Noah, with its default model structure, underestimates the soil moisture content of the top layer under wet conditions and overestimates it during dry-down episodes, whereas the moisture contents in the deeper soil layers are systematically underestimated. Three augmentations to the model physics are investigated to remediate these deficiencies: 1) the impact of organic matter on the soil water retention curve is considered via the additivity hypothesis, 2) the saturated hydraulic conductivity $K_{s}$ is implemented as an exponentially decaying function with soil depth, and 3) the vertical root distribution is modified to better represent the Tibetan alpine grassland conditions characterized by an abundance of roots in the topsoil layer. Further, the diffusivity form of Richards' equation is revised to allow for the simulation of the soil water flow across soil layers with different hydraulic properties.

The modified hydraulic parameterization is compared against laboratory measurements of the soil water retention curve and in situ $K_{s}$ measurements. It is shown that through consideration of organic matter within the class pedotransfer function (PTF) by Cosby et al. (1984), the default option in Noah, the root-mean-square error (RMSE) computed between the estimated and measured porosity $\theta_{s}$ improved by more than $80 \%$ from 0.148 to $0.030 \mathrm{~m}^{3} \mathrm{~m}^{-3}$. This leads to similar improvements in the estimated soil water retention curves of the organic and silt loam soils in SRYR, whereas a slightly reduced performance is noted for the sandy loam soils. The latter is attributed to the fact that the sandy loam soils have little organic matter content, and thus, usage within the parameterization primarily adds uncertainty to the estimates. The $K_{s}$ measurements taken in situ at various soil depths show a decrease by as much as two orders of magnitude across a soil depth from 0.15 to $0.6 \mathrm{~m}$, which is best described with the exponential function combined with the Kozeny-Carman equation.

TABLE 7. Error statistics computed between measured and simulated LE and $H$ as well as temperature at the surface $T_{\mathrm{sfc}}$ and at $25-\mathrm{cm}$ soil depth $T_{\mathrm{s} 25 \mathrm{~cm}}$ produced by three Noah numerical experiments from 8 Jun to 30 Sep 2010.

\begin{tabular}{|c|c|c|c|c|c|c|c|c|}
\hline \multirow[b]{2}{*}{ Expt } & \multicolumn{2}{|c|}{$H\left(\mathrm{~W} \mathrm{~m}^{-2}\right)$} & \multicolumn{2}{|c|}{$\operatorname{LE}\left(\mathrm{W} \mathrm{m}^{-2}\right)$} & \multicolumn{2}{|c|}{$T_{\mathrm{sfc}}(\mathrm{K})$} & \multicolumn{2}{|c|}{$T_{\mathrm{s} 25 \mathrm{~cm}}(\mathrm{~K})$} \\
\hline & RMSE & $\mathrm{ME}$ & RMSE & $\mathrm{ME}$ & RMSE & $\mathrm{ME}$ & RMSE & $\mathrm{ME}$ \\
\hline & 17 & 6.84 & 31.06 & 0.65 & 2.5 & 1.20 & 1.03 & 0.86 \\
\hline XP1 & 18.29 & 7.70 & 30.96 & 0.04 & 2.62 & 1.20 & 1.11 & 0.92 \\
\hline EXP2 & 19.86 & 9.15 & 31.45 & -1.11 & 2.70 & 1.20 & 1.01 & 0.86 \\
\hline
\end{tabular}


water budget ratio to rainfall

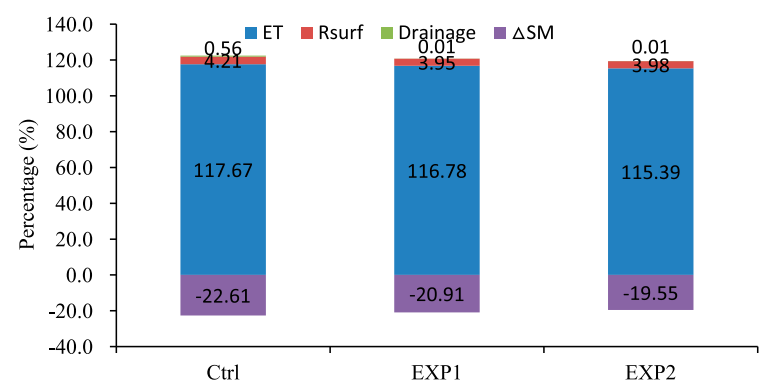

FIG. 7. Comparison of the ratios of different water budget components produced by three Noah numerical experiments (Ctrl, EXP1, and EXP2) presented as a ratio of the rainfall accumulated from 8 Jun to 30 Sep 2010.

Three numerical experiments are designed to assess the impact of the augmentations: 1) a control run with the default model structure (Ctrl), 2) a Noah run with the modified soil hydraulic parameterization (EXP1), and 3) a Noah run with the modified soil hydraulic parameterization and vertical root distribution (EXP2). Through implementation of the modified hydraulic parameterization alone (EXP1), the soil moisture underestimation in the upper soil layer under wet conditions is resolved, whereas the overestimation during dry-downs remains. This somewhat improves the simulations for the deeper soil layers but not to its full extent. By including the modified root distribution in the soil profile, the soil moisture dynamics of the upper layer under dry conditions are better captured, and the simulations of the deeper layers match the measurements better as well. This leads to a reduction in the RMSE computed between the simulated and measured soil moisture by about $49 \%$, $70 \%$, and $56 \%$ for the upper three layers.

The impact of the improved soil moisture simulations on the calculated surface energy and water budgets is assessed and shows that Noah retains more water in the soil column with the augmentations, causing a decrease in the other water balance components. On the other hand, the surface heat flux simulation is hardly affected. This is attributed to the fact that LE in the selected study area and period is primarily constrained by the energy rather than the available soil water.

This study shows through comprehensive measurements performed in the laboratory and field that significant improvements can be achieved in the soil water flow simulation by the Noah LSM for a Tibetan Plateau site through a better representation of the hydraulic parameters and the root distribution across the soil profile. This further confirms the necessity to incorporate the impact of vertical soil heterogeneity caused by organic matter and root systems into state-of-the-art LSMs for their application to the Tibetan Plateau (Chen et al.
2013; Xue et al. 2013; Yang et al. 2005). This study can also be seen as an attempt to investigate the transferability of LSM parameterizations developed for the polar and boreal organic soils (Lawrence and Slater 2008; Letts et al. 2000) to the Third Pole Environment (i.e., Tibetan Plateau).

However, additional work is needed to extend the findings of this study to large spatial domains. The soil property datasets (e.g., soil particle size distribution and soil organic carbon) recently developed for China as well as the globe (Shangguan et al. 2012, 2014, 2013) can, for instance, be utilized for such application. The improved simulated soil moisture information across large areas would greatly enhance our understanding of the hydrologic cycle and assist in preservation of highaltitude ecosystems that are vulnerable to climate change, such as the Tibetan Plateau. Among the other imperatives for the performance of LSMs in the highaltitude ecosystems are robust parameterizations of the cold season processes (i.e., freeze-thaw transitions), which require thorough assessment across the globe to confirm its validity.

Acknowledgments. This study was supported by funding from the FP7 CEOP-AEGIS and CORE-CLIMAX projects funded by the European Commission through the FP7 program, the Chinese Academy of Sciences Fellowship for Young International Scientists (Grant 2012Y1ZA0013), the Key Research Program of the Chinese Academy of Sciences (Grant KZZD-EW-13), and the National Natural Science Foundation of China (Grants 41405079 and 41105003).

\section{APPENDIX}

\section{Soil Pedotransfer Functions}

The soil PTF approach has been widely used to predict hydraulic parameters (e.g., porosity and saturated hydraulic conductivity) from more easily measured soil data, such as texture and organic matter content. The PTFs can be subdivided into class and continuous PTFs: the class PTF predicts the average hydraulic characteristics based on distinct soil texture classes, while the continuous PTF uses measured soil particle size distribution data (e.g., percentages of sand and clay) to calculate these hydraulic parameters.

The average hydraulic characteristics of silt loam, sandy loam, and peat are summarized in Table A1 and are derived from the class PTF as given by Cosby et al. (1984) and Letts et al. (2000). The continuous PTF proposed by Cosby et al. (1984) is described as follows: 
TABLE A1. Average soil hydraulic characteristics predicted by class PTF.

\begin{tabular}{lccccc}
\hline \multicolumn{1}{c}{ Class } & $\theta_{s}\left(\mathrm{~m}^{3} \mathrm{~m}^{-3}\right)$ & $K_{s}\left(10^{-6} \mathrm{~m} \mathrm{~s}^{-1}\right)$ & $\psi_{s}(\mathrm{~m})$ & $b$ & Reference \\
\hline Silt loam & 0.476 & 2.81 & -0.759 & 5.33 & Cosby et al. (1984) \\
Sandy loam & 0.434 & 5.23 & -0.141 & 4.74 & Letts et al. (2000) \\
Fibric peat & 0.93 & 280 & -0.0103 & 2.7 & 6.1 \\
Hemic peat & 0.88 & 2.0 & -0.0102 & 12.0 & \\
Sapric peat & 0.83 & 0.10 & -0.0101 & \\
\hline
\end{tabular}

$$
\begin{aligned}
\theta_{s} & =0.489-0.00126(\text { sand }), \\
K_{s} & =7.0556 \times 10^{-6.884+0.0153(\text { sand })}, \\
\psi_{s} & =-0.01 \times 10^{1.88-0.0131(\text { sand })}, \text { and } \\
b & =2.91+0.159(\text { clay }),
\end{aligned}
$$

where $\theta_{s}$ is the porosity $\left(\mathrm{m}^{3} \mathrm{~m}^{-3}\right), K_{s}$ is the saturated hydraulic conductivity $\left(\mathrm{m} \mathrm{s}^{-1}\right), \psi_{s}$ is the soil water potential at air entry $(\mathrm{m}), b$ is an empirical parameter (unitless), sand is the percentage of sand in the soil particle (\%), and clay is the percentage of clay (\%).

\section{REFERENCES}

Ahuja, L. R., J. W. Naney, R. E. Green, and D. R. Nielsen, 1984: Macroporosity to characterize spatial variability of hydraulic conductivity and effects of land management. Soil. Sci. Soc. Amer. J., 48, 699-702, doi:10.2136/sssaj1984.03615995004800040001x.

Balsamo, G., A. Beljaars, K. Scipal, P. Viterbo, B. van den Hurk, M. Hirschi, and A. K. Betts, 2009: A revised hydrology for the ECMWF model: Verification from field site to terrestrial water storage and impact in the integrated forecast system. J. Hydrometeor., 10, 623-643, doi:10.1175/2008JHM1068.1.

Beringer, J., A. H. Lynch, F. S. Chapin, M. Mack, and G. B. Bonan, 2001: The representation of Arctic soils in the land surface model: The importance of mosses. J. Climate, 14, 3324-3335, doi:10.1175/1520-0442(2001)014<3324:TROASI >2.0.CO;2.

Beven, K., 1982: On subsurface stormflow: An analysis of response times. Hydrol. Sci. J., 27, 505-521, doi:10.1080/02626668209491129.

Braun, F. J., and G. Schädler, 2005: Comparison of soil hydraulic parameterizations for mesoscale meteorological models. J. Appl. Meteor., 44, 1116-1132, doi:10.1175/JAM2259.1.

Campbell, G. S., 1974: A simple method for determining unsaturated conductivity from moisture retention data. Soil Sci., 117, 311-314, doi:10.1097/00010694-197406000-00001.

Carey, S. K., W. L. Quinton, and N. T. Goeller, 2007: Field and laboratory estimates of pore size properties and hydraulic characteristics for subarctic organic soils. Hydrol. Processes, 21, 2560-2571, doi:10.1002/hyp.6795.

Chen, F., and Coauthors, 1996: Modeling of land surface evaporation by four schemes and comparison with FIFE observations. J. Geophys. Res., 101, 7251-7268, doi:10.1029/95JD02165.

Chen, J., and P. Kumar, 2001: Topographic influence on the seasonal and interannual variation of water and energy balance of basins in North America. J. Climate, 14, 1989-2014, doi:10.1175/ 1520-0442(2001)014<1989:TIOTSA > 2.0.CO;2.

Chen, Y., K. Yang, W. Tang, J. Qin, and L. Zhao, 2012: Parameterizing soil organic carbon's impacts on soil porosity and thermal parameters for eastern Tibet grasslands. Sci. China Earth Sci., 55, 1001-1011, doi:10.1007/s11430-012-4433-0.
,-- J. Jin, L. Zhao, W. Tang, and M. Han, 2013: Evaluation of AMSR-E retrievals and GLDAS simulations against observations of a soil moisture network on the central Tibetan Plateau. J. Geophys. Res. Atmos., 118, 4466-4475, doi:10.1002/jgrd.50301.

Clapp, R. B., and G. M. Hornberger, 1978: Empirical equations for some soil hydraulic properties. Water Resour. Res., 14, 601604, doi:10.1029/WR014i004p00601.

Cosby, B. J., G. M. Hornberger, R. B. Clapp, and T. R. Ginn, 1984: A statistical exploration of the relationships of soil moisture characteristics to the physical properties of soils. Water Resour. Res., 20, 682-690, doi:10.1029/WR020i006p00682.

Dai, Y., and Coauthors, 2003: The Common Land Model. Bull. Amer. Meteor. Soc., 84, 1013-1023, doi:10.1175/BAMS-84-8-1013.

Decharme, B., H. Douville, A. Boone, F. Habets, and J. Noilhan, 2006: Impact of an exponential profile of saturated hydraulic conductivity within the ISBA LSM: Simulations over the Rhône basin. J. Hydrometeor., 7, 61-80, doi:10.1175/ JHM469.1.

_ A. Boone, C. Delire, and J. Noilhan, 2011: Local evaluation of the interaction between Soil Biosphere Atmosphere soil multilayer diffusion scheme using four pedotransfer functions. J. Geophys. Res., 116, D20126, doi:10.1029/2011JD016002.

Decker, M., M. A. Brunke, Z. Wang, K. Sakaguchi, X. Zeng, and M. G. Bosilovich, 2012: Evaluation of the reanalysis products from GSFC, NCEP, and ECMWF using flux tower observations. J. Climate, 25, 1916-1944, doi:10.1175/JCLI-D-11-00004.1.

Dente, L., Z. Vekerdy, J. Wen, and Z. Su, 2012: Maqu network for validation of satellite-derived soil moisture products. Int. J. Appl. Earth Obs. Geoinf., 17, 55-65, doi:10.1016/j.jag.2011.11.004.

de Vries, D. A., 1963: Thermal properties of soils. Physics of Plant Environment, W. R. van Wijk, Ed., North-Holland, 210-235.

Dirmeyer, P. A., Z. Guo, and X. Gao, 2004: Comparison, validation, and transferability of eight multiyear global soil wetness products. J. Hydrometeor., 5, 1011-1033, doi:10.1175/JHM-388.1.

_ X. Gao, M. Zhao, Z. Guo, T. Oki, and N. Hanasaki, 2006a: GSWP-2: Multimodel analysis and implications for our perception of the land surface. Bull. Amer. Meteor. Soc., 87, 13811397, doi:10.1175/BAMS-87-10-1381.

— , R. D. Koster, and Z. Guo, 2006b: Do global models properly represent the feedback between land and atmosphere? J. Hydrometeor., 7, 1177-1198, doi:10.1175/JHM532.1.

Ek, M. B., and Coauthors, 2003: Implementation of Noah land surface model advances in the National Centers for Environmental Prediction operational mesoscale Eta Model. J. Geophys. Res., 108, 8851, doi:10.1029/2002JD003296.

Famiglietti, J. S., and E. F. Wood, 1994: Multiscale modeling of spatially variable water and energy balance processes. Water Resour. Res., 30, 3061-3078, doi:10.1029/94WR01498.

Federer, C. A., D. E. Turcotte, and C. T. Smith, 1993: The organic fraction-bulk density relationship and the expression of nutrient content in forest soils. Can. J. For. Res., 23, 1026-1032, doi:10.1139/ x93-131. 
Gale, M. R., and D. F. Grigal, 1987: Vertical root distributions of northern tree species in relation to successional status. Can. J. For. Res., 17, 829-834, doi:10.1139/x87-131.

Gulden, L. E., E. Rosero, Z.-L. Yang, M. Rodell, C. S. Jackson, G.-Y. Niu, P. J.-F. Yeh, and J. Famiglietti, 2007: Improving landsurface model hydrology: Is an explicit aquifer model better than a deeper soil profile? Geophys. Res. Lett., 34, L09402, doi:10.1029/2007GL029804.

Hills, R. G., I. Porro, D. B. Hudson, and P. J. Wierenga, 1989: Modeling one-dimensional infiltration into very dry soils: 1 . Model development and evaluation. Water Resour. Res., 25 1259-1269, doi:10.1029/WR025i006p01259.

IPCC, 2013: Climate Change 2013: The Physical Science Basis. Cambridge University Press, 1535 pp.

Jackson, R. B., J. Canadell, J. R. Ehleringer, H. A. Mooney, O. E. Sala, and E. D. Schulze, 1996: A global analysis of root distributions for terrestrial biomes. Oecologia, 108, 389-411, doi:10.1007/BF00333714.

Jiménez, C., and Coauthors, 2011: Global intercomparison of 12 land surface heat flux estimates. J. Geophys. Res., 116, D02102, doi:10.1029/2010JD014545.

Koren, V., J. Schaake, K. Mitchell, Q. Y. Duan, F. Chen, and J. M. Baker, 1999: A parameterization of snowpack and frozen ground intended for NCEP weather and climate models. J. Geophys. Res., 104, 19569-19585, doi:10.1029/1999JD900232.

Lawrence, D. M., and A. G. Slater, 2008: Incorporating organic soil into a global climate model. Climate Dyn., 30, 145-160 doi:10.1007/s00382-007-0278-1.

_ - and Coauthors, 2011: Parameterization improvements and functional and structural advances in version 4 of the Community Land Model. J. Adv. Model. Earth Syst., 3, M03001, doi:10.1029/2011MS000045.

Letts, M. G., N. T. Roulet, N. T. Comer, M. R. Skarupa, and D. L. Verseghy, 2000: Parametrization of peatland hydraulic properties for the Canadian land surface scheme. Atmos.-Ocean, 38, 141-160, doi:10.1080/07055900.2000.9649643.

Li, K. Y., R. De Jong, and J. B. Boisvert, 2001: An exponential root-water-uptake model with water stress compensation. J. Hydrol., 252, 189-204, doi:10.1016/S0022-1694(01)00456-5.

Liang, X., E. F. Wood, and D. P. Lettenmaier, 1996: Surface soil moisture parameterization of the VIC-2L model: Evaluation and modification. Global Planet. Change, 13, 195-206, doi:10.1016/0921-8181(95)00046-1.

Mahrt, L., and M. Ek, 1984: The influence of atmospheric stability on potential evaporation. J. Climate Appl. Meteor., 23, 222-234, doi:10.1175/1520-0450(1984)023<0222:TIOASO > 2.0.CO;2.

— Bound.-Layer Meteor., 29, 1-20, doi:10.1007/BF00119116.

Manabe, S., 1969: Climate and the ocean circulation. Mon. Wea. Rev., 97, 739-774, doi:10.1175/1520-0493(1969)097<0739:CATOC >2.3.CO;2.

Nemes, A., W. J. Rawls, and Y. A. Pachepsky, 2005: Influence of organic matter on the estimation of saturated hydraulic conductivity. Soil. Sci. Soc. Amer. J., 69, 1330-1337, doi:10.2136/ sssaj2004.0055.

Niu, G.-Y., and Coauthors, 2011: The community Noah land surface model with multiparameterization options (NoahMP): 1. Model description and evaluation with local-scale measurements. J. Geophys. Res., 116, D12109, doi:10.1029/ 2010JD015139.

Pan, H. L., and L. Mahrt, 1987: Interaction between soil hydrology and boundary-layer development. Bound-Layer Meteor., 38 , 185-202, doi:10.1007/BF00121563.
Peters-Lidard, C. D., E. Blackburn, X. Liang, and E. F. Wood, 1998: The effect of soil thermal conductivity parameterization on surface energy fluxes and temperatures. J. Atmos. Sci. 55, 1209-1224, doi:10.1175/1520-0469(1998)055<1209:TEOSTC $>2.0 . C O ; 2$.

Rinke, A., P. Kuhry, and K. Dethloff, 2008: Importance of a soil organic layer for Arctic climate: A sensitivity study with an Arctic RCM. Geophys. Res. Lett., 35, L13709, doi:10.1029/ 2008 GL034052.

Rodell, M., and Coauthors, 2004: The Global Land Data Assimilation System. Bull. Amer. Meteor. Soc., 85, 381-394, doi:10.1175/ BAMS-85-3-381.

Saxton, K. E., and W. J. Rawls, 2006: Soil water characteristic estimates by texture and organic matter for hydrologic solutions. Soil. Sci. Soc. Amer. J., 70, 1569-1578, doi:10.2136/ sssaj2005.0117.

Schaake, J. C., V. I. Koren, Q.-Y. Duan, K. Mitchell, and F. Chen, 1996: Simple water balance model for estimating runoff at different spatial and temporal scales. J. Geophys. Res., 101, 7461-7475, doi:10.1029/95JD02892.

Sellers, P. J., Y. Mintz, Y. C. Sud, and A. Dalcher, 1986: A Simple Biosphere Model (SIB) for use within general circulation models. J. Atmos. Sci., 43, 505-531, doi:10.1175/1520-0469(1986)043<0505: ASBMFU $>2.0 . \mathrm{CO} ; 2$

Shangguan, W., Y. Dai, B. Liu, A. Ye, and H. Yuan, 2012: A soil particle-size distribution dataset for regional land and climate modelling in China. Geoderma, 171-172, 85-91, doi:10.1016/j.geoderma.2011.01.013.

— - and Coauthors, 2013: A China data set of soil properties for land surface modeling. J. Adv. Model. Earth Syst., 5, 212-224, doi:10.1002/jame.20026.

—, Y. Dai, Q. Duan, B. Liu, and H. Yuan, 2014: A global soil data set for earth system modeling. J. Adv. Model. Earth Syst., 6, 249-263, doi:10.1002/2013MS000293.

Shao, Y., and P. Irannejad, 1999: On the choice of soil hydraulic models in land-surface schemes. Bound.-Layer Meteor., 90, 83-115, doi:10.1023/A:1001786023282.

Stieglitz, M., D. Rind, J. Famiglietti, and C. Rosenzweig, 1997: An efficient approach to modeling the topographic control of surface hydrology for regional and global climate modeling. J. Climate, 10, 118-137, doi:10.1175/1520-0442(1997)010<0118: AEATMT $>2.0 . C O ; 2$.

Su, Z., and Coauthors, 2011: The Tibetan Plateau observatory of plateau scale soil moisture and soil temperature (Tibet-Obs) for quantifying uncertainties in coarse resolution satellite and model products. Hydrol. Earth Syst. Sci., 15, 2303-2316, doi:10.5194/ hess-15-2303-2011.

— , P. de Rosnay, J. Wen, L. Wang, and Y. Zeng, 2013: Evaluation of ECMWF's soil moisture analyses using observations on the Tibetan Plateau. J. Geophys. Res. Atmos., 118, 5304-5318, doi:10.1002/jgrd.50468.

van der Velde, R., Z. Su, M. Ek, M. Rodell, and Y. Ma, 2009: Influence of thermodynamic soil and vegetation parameterizations on the simulation of soil temperature states and surface fluxes by the Noah LSM over a Tibetan Plateau site. Hydrol. Earth Syst. Sci., 13, 759-777, doi:10.5194/hess-13-759-2009.

Xia, Y., and Coauthors, 2014: Evaluation of multi-model simulated soil moisture in NLDAS-2. J. Hydrol., 512, 107-125, doi:10.1016/j.jhydrol.2014.02.027.

Xue, B.-L., and Coauthors, 2013: Modeling the land surface water and energy cycles of a mesoscale watershed in the central Tibetan Plateau during summer with a distributed hydrological model. J. Geophys. Res. Atmos., 118, 8857-8868, doi:10.1002/jgrd.50696. 
Yang, K., T. Koike, B. Ye, and L. Bastidas, 2005: Inverse analysis of the role of soil vertical heterogeneity in controlling surface soil state and energy partition. J. Geophys. Res., 110, D08101, doi:10.1029/2004JD005500.

—_ and Coauthors, 2013: A multiscale soil moisture and freezethaw monitoring network on the third pole. Bull. Amer. Meteor. Soc., 94, 1907-1916, doi:10.1175/BAMS-D-12-00203.1.

Yang, Y., J. Fang, C. Ji, and W. Han, 2009a: Above- and belowground biomass allocation in Tibetan grasslands. J. Veg. Sci., 20, 177-184, doi:10.1111/j.1654-1103.2009.05566.x.

— , and Coauthors, 2009b: Changes in topsoil carbon stock in the Tibetan grasslands between the 1980s and 2004. Global Change Biol., 15, 2723-2729, doi:10.1111/j.1365-2486.2009.01924.x.

Zeiliguer, A. M., Y. A. Pachepsky, and W. J. Rawls, 2000: Estimating water retention of sandy soils using the additivity hypothesis. Soil Sci., 165, 373-383, doi:10.1097/ 00010694-200005000-00001.

Zeng, X., 2001: Global vegetation root distribution for land modeling. J. Hydrometeor., 2, 525-530, doi:10.1175/ 1525-7541(2001)002<0525:GVRDFL>2.0.CO;2.

Zheng, D., R. van der Velde, Z. Su, M. J. Booij, A. Y. Hoekstra, and J. Wen, 2014: Assessment of roughness length schemes implemented within the Noah land surface model for highaltitude regions. J. Hydrometeor., 15, 921-937, doi:10.1175/ JHM-D-13-0102.1.

, X. Wang, J. Wen, M. J. Booij, A. Y. Hoekstra, and Y. Chen, 2015: Augmentations to the Noah model physics for application to the Yellow River source area. Part II: Turbulent heat fluxes and soil heat transport. J. Hydrometeor., 16, 26772694, doi:10.1175/JHM-D-14-0199.1. 